NBER WORKING PAPER SERIES

\title{
QUANTITATIVE MACROECONOMICS WITH HETEROGENEOUS HOUSEHOLDS
}

\author{
Jonathan Heathcote \\ Kjetil Storesletten \\ Giovanni L. Violante \\ Working Paper 14768 \\ http://www.nber.org/papers/w14768
}

\author{
NATIONAL BUREAU OF ECONOMIC RESEARCH \\ 1050 Massachusetts Avenue \\ Cambridge, MA 02138 \\ March 2009
}

This paper was prepared for Volume 1 of the Annual Review of Economics. Heathcote and Violante thank the National Science Foundation (Grant SES-0418029). The views expressed herein are those of the authors and not necessarily those of the Federal Reserve Bank of Minneapolis, the Federal Reserve System, or the National Bureau of Economic Research.

NBER working papers are circulated for discussion and comment purposes. They have not been peerreviewed or been subject to the review by the NBER Board of Directors that accompanies official NBER publications.

(C) 2009 by Jonathan Heathcote, Kjetil Storesletten, and Giovanni L. Violante. All rights reserved. Short sections of text, not to exceed two paragraphs, may be quoted without explicit permission provided that full credit, including $(\mathcal{C}$ notice, is given to the source. 
Quantitative Macroeconomics with Heterogeneous Households

Jonathan Heathcote, Kjetil Storesletten, and Giovanni L. Violante

NBER Working Paper No. 14768

March 2009

JEL No. E2,J22

\begin{abstract}
$\underline{\text { ABSTRACT }}$
Macroeconomics is evolving from the study of aggregate dynamics to the study of the dynamics of the entire equilibrium distribution of allocations across individual economic actors. This article reviews the quantitative macroeconomic literature that focuses on household heterogeneity, with a special emphasis on the "standard" incomplete markets model. We organize the vast literature according to three themes that are central to understanding how inequality matters for macroeconomics. First, what are the most important sources of individual risk and cross-sectional heterogeneity? Second, what are individuals' key channels of insurance? Third, how does idiosyncratic risk interact with aggregate risk?
\end{abstract}

Jonathan Heathcote

Federal Reserve Bank of Minneapolis

Research Department

90 Hennepin Ave.

Minneapolis, MN 55401

heathcote@minneapolisfed.org

Kjetil Storesletten

Department of Economics

University of Oslo

Box 1095 Blindern

$\mathrm{N}-0317$ Oslo

Norway

kjetil.storesletten@econ.uio.no
Giovanni L. Violante

Department of Economics

New York University

19 W. 4th Street

New York, NY 10012-1119

and NBER

glv2@nyu.edu 


\section{Introduction}

The embrace of heterogeneity by macroeconomists is rooted in the "rational expectations revolution." Until the 1970s, the field of macroeconomics concentrated on estimating systems of ad hoc aggregate relationships ("Cowles macroeconometrics") and largely abstracted from individual behavior and differences across economic agents. Lucas, Sargent, and Wallace, among others, transformed the agenda in macroeconomics, shifting the focus to dynamic stochastic general equilibrium models grounded in optimal individual decision making. However, the first generation of quantitative macroeconomic models, which followed the influential work of Kydland and Prescott (1982), was built on the representative agent paradigm. The most important reason for this choice was that economists lacked the tools to solve dynamic models with heterogeneous agents and incomplete markets. In addition, it was not obvious that incorporating household or firm heterogeneity was of first-order importance for understanding the business cycle dynamics of aggregate quantities and prices, or long-run economic growth.

Over the last two decades, faster computers and improvements in numerical methods have made it possible to study rich heterogeneous agent models. In addition, microeconometric work in labor economics and industrial organization has revealed enormous cross-sectional dispersion and individual volatility for workers and firms. As Heckman (2001, p. 256) puts it: "The most important discovery was the evidence on the pervasiveness of heterogeneity and diversity in economic life." Macroeconomists reached several conclusions about the importance of including household heterogeneity in their models. These insights cast serious doubts on the use of the representative-agent abstraction when studying macroeconomics.

First, heterogeneity affects both the levels and dynamics of aggregate equilibrium quantities and prices. For instance, idiosyncratic uninsurable income risk implies a precautionary motive for saving that increases aggregate wealth and reduces the equilibrium interest rate (Huggett 1993). Heathcote (2005) finds that changes in the timing of taxes that would be neutral in a representative agent model (Ricardian equivalence) turn out to have large real effects in a model with heterogeneous agents and incomplete markets. As a final example, in an environment with endogenous labor supply, changes in the magnitude and insurability of idiosyncratic risk affect aggregate labor productivity (Heathcote et al. 2008a).

Second, introducing heterogeneity can change the answer to welfare questions. Lucas (1987) showed that for standard preferences, aggregate fluctuations have a very small impact on the 
welfare of a representative consumer. At face value, the Lucas calculation suggested that surprisingly little was at stake in the traditional macroeconomic topics of business cycles and stabilization policy. One reason such a conclusion seemed premature is that economies with incomplete markets present a natural environment in which aggregate fluctuations can have asymmetric welfare effects across heterogeneous agents. In Storesletten et al. (2001), for example, liquidity constrained households are particularly hard hit by aggregate productivity shocks. Moreover, the average cross-sectional welfare cost of aggregate fluctuations can be much larger than the cost for a hypothetical representative agent.

Third, and perhaps more importantly, many macro questions of great relevance simply can not be addressed without allowing for at least some heterogeneity. For example, to study social security requires a model in which agents differ by age. Auerbach and Kotlikoff's (1987) book was one of the first quantitative applications of the overlapping generations framework to study fiscal and social security policy and demographic change. One of the key macroeconomic trends of the recent past is the dramatic widening of the wage structure in the United States (US, hereafter) over the period 1975-1995. Average real wages for men barely changed, but wage dispersion within and between education groups increased dramatically. These trends and their implications for policy and welfare can only be explored within heterogeneous agent models of the macroeconomy (e.g., Heathcote et al. 2008b; Krueger and Perri 2006).

More broadly, macroeconomics is expanding from the study of how average values for the inputs (capital and labor) and outputs (consumption) of production are determined in equilibrium to the study of how the entire distribution of these variables across households is determined. This expansion is crucial for policy analysis, for two reasons. First, volatility at the level of individual workers and firms is orders of magnitude larger than aggregate volatility. Thus, the welfare implications of policies that redistribute across agents are potentially much larger than the implications of policies aimed at stabilizing the aggregates. Second, the evaluation of largescale government programs (e.g., social insurance, tuition subsidies) requires models that take into account both general equilibrium effects and the heterogeneous impact of policies across the population (Heckman 2001).

The standard incomplete markets model Currently, the main workhorse for studying heterogeneity (across people) in macroeconomics is what we will call the "standard incomplete markets" (SIM) model. Our article is centered on this framework, which we present in detail 
in Section 2. In the SIM model, a large number of agents draw idiosyncratic realizations for productivity, and make independent choices for consumption, savings, and, in some versions, labor supply. In aggregate, their choices determine the total amount of capital and effective labor available for production and, thus, equilibrium prices.

This framework was a natural starting point for introducing heterogeneity into macroeconomics, from both a micro and a macro perspective. On the one hand, it embedded the familiar income fluctuations problem at the heart of Friedman's permanent income hypothesis in a multiple agent, general equilibrium framework. On the other, it fits well with the stochastic growth model that dominates the business cycle literature: agents maximize expected lifetime utility in response to exogenous shocks to productivity by adjusting consumption, hours, and capital accumulation, the only difference being that the SIM model incorporates shocks at the individual level instead of (or in addition to) the aggregate level.

Over the years, this baseline SIM framework was extended in several directions, which we discuss in detail in our article. All these variants share two common characteristics. First, they feature imperfect insurance. Second, they incorporate the risk-sharing mechanisms observed in actual economies. An alternative to the first feature is to introduce heterogeneity while maintaining perfect insurance. An alternative to the second is to look for allocations that maximize risk sharing subject to fundamental informational or enforcement frictions.

Heterogeneity with complete markets The smallest possible deviation from the representative agent framework is to model heterogeneity in an environment with complete markets. If, in addition, preferences are homothetic, then some sources of heterogeneity become irrelevant. More precisely, even though agents may differ by initial tastes, skills, or wealth, and are subject to idiosyncratic (but insurable) shocks, the economy aggregates in the sense that macro aggregates do not depend on the wealth distribution. ${ }^{1}$ It is important to note, however, that the representative agent that emerges in aggregation need not share the utility function of the agents in the original heterogeneous agents economy. A well-known example is the indivisible labor economies of Hansen (1985) and Rogerson (1988), where there is no connection between the aggregate and individual labor supply elasticities. ${ }^{2}$

\footnotetext{
${ }^{1}$ Chatterjee (1994) explores the dynamics of wealth inequality in a model with common preferences but with initial wealth dispersion. Caselli and Ventura (2000) add heterogeneity in initial tastes and skills, and characterize the joint evolution of distributions and averages for consumption, income, and wealth.

${ }^{2}$ Maliar and Maliar (2003) is another example. They extend the Chatterjee environment to allow for id-
} 
Relying on the assumption of complete markets is unattractive for a number of reasons. To many economists, market completeness seems implausible a priori as a literal description of the world. From an empirical standpoint, the assumption of complete markets is routinely rejected at different levels. First, there is evidence that changes in earnings pass through to consumption (e.g., Attanasio and Davis 1996). Second, when agents have identical preferences, complete markets imply that there should be no consumption mobility. There is, however, evidence of such mobility (see Fisher and Johnson 2006, for the US; Jappelli and Pistaferri 2006, for Italy). As Lucas (1992) puts it, "If the children of Noah had been able and willing to pool risks, Arrow-Debreu style, among themselves and their descendants, then the vast inequality we see today, within and across societies, would not exist." Restricting attention to models where the initial ranking of individuals is preserved forever would be a major limitation for a research program that aims at understanding the dynamics of inequality.

Modeling market incompleteness Abandoning the complete markets benchmark, however, raises a fundamental question. How should market incompleteness be modeled? The SIM approach is to simply model the markets, institutions, and arrangements that are observed in actual economies. The main virtue of this "model what you can see" approach is that it is easy to map model allocations into empirical counterparts, because the decentralized competitive equilibrium is characterized directly. As a result, it is straightforward to enrich the model in various dimensions to tailor it to specific applications. The main drawback of the approach is that it is unclear why markets are incomplete in the first place. Why can agents not find better ways to insure each other, in the spirit of Coase?

The other view is that the scope for risk sharing should be derived endogenously, subject to the deep frictions that prevent full insurance. The "model what you can microfound" literature has focused on information frictions (providing insurance to an agent with unobservable type or action, as in Attanasio and Pavoni 2008) and enforcement frictions (providing insurance to an agent who can walk away from contracts, as in Krueger and Perri 2006). In these models, risk sharing responds to changes in the environment, which is appealing since policyexperiments are less vulnerable to a version of the Lucas critique. In particular, the endogenous incomplete markets approach explicitly recognizes that changes in public insurance programs are likely to

iosyncratic but insurable productivity shocks, and show that aggregate dynamics correspond to those of a representative agent economy subject to "aggregate shocks" which are a function of higher moments of the distribution of idiosyncratic shocks. 
change incentives for private insurance provision. ${ }^{3}$ However, these models have an important limitation. They often imply substantial state-contingent transfers between agents for which there is no obvious empirical counterpart.

We conclude this discussion by noting that the "model what you can see" and "model what you can microfound" approaches can be combined. For example, in Section 4 we will discuss a class of models in which the set of assets traded is specified exogenously, but borrowing costs are determined endogenously, as a function of default incentives (e.g., Chatterjee et al. 2007). Arguably, this approach combines the best of both worlds: the greater realism of the SIM approach, and the trade-off between providing risk sharing while preserving incentives from the endogenous incompleteness approach.

Three themes The first generation of SIM models allowed for only a narrow set of sources of heterogeneity, and a limited number of avenues for partially insuring idiosyncratic risk. Agents were ex ante identical and ex post heterogeneous only because of exogenous shocks to income. Risk-free bonds were the only avenue of insurance. Aggregate shocks were either entirely absent or limited to some special cases that preserved tractability. Fortunately, the basic SIM framework turned out to be sufficiently tractable to incorporate (i) additional sources of risk, (ii) more channels of insurance, and (iii) aggregate risk. The three main themes of this article illustrate how the literature is developing along these three dimensions.

Our first theme (Section 3) centers on the sources of heterogeneity and inequality. At a broad level, individuals differ with respect to initial innate characteristics (e.g., earning ability, health status, and preferences), and experience different sequences of shocks during their lifetimes. For policy design, it is paramount to understand what is the importance of initial endowments relative to subsequent shocks in determining overall inequality. In addition, it is important to recognize that, among what economists measure as shocks, there may be anticipated changes for which individuals were prepared. Finally, a key decision is how deep to dig in microfounding individual income fluctuations. The early literature treated them as pure endowment shocks, but for some questions it is important to recognize that earnings have an endogenous component reflecting choices about labor supply, human capital accumulation, and job search behavior.

Our second theme (Section 4) centers on assessing individuals' key channels of insurance.

\footnotetext{
${ }^{3}$ For example, Attanasio and Ríos-Rull (2000) illustrate that an increase in government-provided insurance, though a safety net, will crowd out within-family insurance and may lower agents' overall ability to smooth consumption.
} 
In addition to risk-free debt, households can invest in a range of alternative assets to hedge various risks, and can buy explicit insurance against others. The option to declare bankruptcy introduces an additional element of state contingency in financial markets. While the fiction of the infinitely lived "bachelor household" has offered many valuable insights, explicitly modeling the family allows one to incorporate many important avenues of insurance: pooling of imperfectly correlated individual risk within the household, opportunities for time reallocation in response to shocks, and inter vivos transfers and bequests. Finally, the government offers additional risk sharing via redistributive taxation and various social insurance programs. It is obviously important to understand the relative importance of different channels of insurance, and the extent to which they substitute or complement each other.

Our third theme (Section 5) is the interaction between idiosyncratic risk and aggregate dynamics. A number of papers suggest that changes in the size of idiosyncratic uncertainty can have large effects on aggregate prices, quantities, and productivity, reflecting the way households' saving and labor supply decisions respond to such changes. At the same time, a range of classical topics in macroeconomics, including the equity premium puzzle, the welfare cost of business cycles, and the optimal design of fiscal stabilization policies, have been reexamined in models that feature idiosyncratic risk in addition to aggregate fluctuations. Valuable progress is being made toward understanding the conditions on the interaction between idiosyncratic and aggregate risk under which heterogeneity changes the implications of theory for these issues. Finally, macroeconomists are beginning to explore common sources for both aggregate and idiosyncratic uncertainty.

\section{The standard incomplete markets model}

This section presents, mostly verbally, the structure of the standard incomplete markets (SIM) model and some of its key properties. For a more technical description of the environment and a definition of equilibrium, we refer the reader to Ríos-Rull (1995), Ljungqvist and Sargent (2004), and Krusell and Smith (2006).

The income fluctuation problem The main building block of the model is the so-called income fluctuation problem, the problem of characterizing the optimal consumption sequence for a household facing stochastic income fluctuations. The typical environment is as follows. 
Time is discrete and indexed by $t=0,1, \ldots$. An infinitely lived household with discount factor $\beta<1$ and time-separable preferences derives utility from streams of consumption $\left\{c_{t}\right\}_{t=0}^{\infty}$. Period utility, $u\left(c_{t}\right)$, is strictly concave, strictly increasing, and differentiable. The household faces a stochastic income endowment, $y_{t}$, with bounded support. There are no state-contingent securities to insure idiosyncratic endowment risk, only a risk-free asset, $a_{t}$, which yields a constant gross interest rate $R$. The household can save and can borrow up to some exogenous limit (which could be zero), but no default is allowed.

In order to smooth consumption, the household "self-insures" by accumulating and decumulating assets. As in Friedman's permanent income hypothesis, consumption responds strongly to permanent earnings shocks but very little to transitory ones. We will return to the important question of how effectively the household can smooth consumption. The notion of precautionary savings distinguishes this class of models from the strict version of the permanent income hypothesis, where agents have quadratic utility and face no debt limit, except for a no-Ponzi game condition. Precautionary saving describes saving undertaken to build a buffer against the risk of future endowment drops. ${ }^{4}$

There are, unfortunately, few general results that apply to this class of problems. One important implication of the precautionary motive is that if $\beta R \geq 1$, then there is no upper bound to households' optimal asset accumulation. ${ }^{5}$ Additional conditions are required to guarantee that wealth is bounded when $\beta R<1$. Schechtman and Escudero (1977) prove that decreasing absolute risk aversion is sufficient in the independently and identically distributed (i.i.d.) case. Intuitively, one needs the precautionary motive to weaken as individual assets grow, i.e., agents must become less and less concerned about income uncertainty as they get rich. Huggett (1993) generalizes this argument to a setting where agents have constant relative risk aversion (CRRA) utility and their labor income follows a two-state Markov chain. ${ }^{6}$

\footnotetext{
${ }^{4}$ Precautionary savings is defined as the increase in agents' accumulated wealth that would obtain when switching from a deterministic income path to a stochastic income process. The early literature, summarized in Kimball (1990), argued that the precautionary saving motive is active if the third derivative of the period utility function is positive ("prudence"). However, precautionary saving arises even without a positive third derivative, as long as households are risk-averse and face a borrowing limit that can bind due to risk.

${ }^{5}$ The result was proved in a setting without borrowing by Schechtman (1976) for the case where labor income is i.i.d., and by Bewley (1977) for any stationary process. Chamberlain and Wilson (2000) generalize it for any stochastic process, and any arbitrary borrowing limit - as long as agents repay with probability one.

${ }^{6}$ The only additional condition needed is the monotonicity of the Markov process, namely, that if the state at date $t$ is good, then the lottery for date $t+1$ is better, in terms of first-order stochastic dominance, than it would have been had the state been bad at date $t$. Any income process with positive autocorrelation delivers this property.
} 
Equilibrium with many agents The next step in the analysis of the model is to characterize the behavior of an economy populated by a continuum of households facing independent uninsurable fluctuations in their endowments. In the benchmark model, aggregates are constant - we defer the analysis of aggregate risk to Section 5. Households have identical preferences. They can turn a unit of their endowment into a unit of the consumption good (the numeraire), or trade it in the asset market in exchange for a promise of $R$ units of consumption next period - a one-period bond contract.

Characterizing a steady state in this economy means finding (i) a stationary distribution for household wealth, where wealth dispersion reflects different histories for the endowment shock, and (ii) an interest rate $R^{*}$ that clears the asset market by equating net aggregate asset demand to net asset supply, as in a standard Lucas (1978) tree economy. Net aggregate demand is obtained by integrating all the (positive and negative) wealth holdings of households with respect to the stationary distribution.

Early work by Laitner (1979) and Bewley (1983) proves existence of an equilibrium where the net interest rate $\left(R^{*}-1\right)$ is strictly below the discount rate $(1 / \beta-1) \cdot{ }^{7}$ As discussed above, households save more than under complete markets for precautionary motives. This pushes the interest rate below the complete markets level (i.e., the discount rate). In turn, it is precisely a low interest rate that limits households' desire for saving and prevents the aggregate demand for assets from growing without bound. ${ }^{8}$

In order to guarantee uniqueness of the steady-state wealth distribution, for a given interest rate, the economy must satisfy the "monotone mixing condition," which guarantees sufficient upward and downward social mobility. Ruling out multiple invariant distributions is necessary to ensure continuity of the net aggregate demand function with respect to the interest rate, hence existence of an equilibrium. ${ }^{9}$

With complete markets, the wealth distribution is indeterminate, even though the steadystate interest rate and capital stock are unique. In contrast, under the conditions discussed above, the SIM model has a unique invariant cross-sectional distribution, featuring mobility

\footnotetext{
${ }^{7}$ This early work by Bewley led Ljungqvist and Sargent (2004) to adopt the term "Bewley models." We chose to use the expression "standard incomplete markets models" because our review covers a large and expanding literature that builds on, but goes far beyond, Bewley's original contributions.

${ }^{8}$ See Huggett and Ospina (2001) and Flodén (2008) for further discussion of aggregate savings in general equilibrium.

${ }^{9}$ However, even if there is a unique wealth distribution for any given interest rate, it is difficult to prove that net asset demand is monotone with respect to $R$, which would guarantee equilibrium uniqueness.
} 
of individuals across income, consumption, and wealth classes. Such sharp predictions for the distribution of allocations make SIM an attractive and natural framework for studying the determinants and dynamics of inequality.

Extending the benchmark model The benchmark model has been extended in a number of important directions. Aiyagari (1994) embedded the model in a neoclassical production economy, with a representative firm operating a constant returns to scale technology using physical capital and efficiency units of labor in the production of the final (consumption and investment) good. By assuming a closed economy, so that aggregate investment equals aggregate saving, Aiyagari could pin down the capital stock and the equilibrium interest rate.

A key extension, in terms of adding realism, was to add a life cycle dimension to the SIM framework (Imrohoroglu et al. 1995; Ríos-Rull 1995; Huggett 1996). ${ }^{10}$ The main advantage of these life cycle models is that they can be tailored to capture salient features of the data, such as an increasing age productivity profile inducing life cycle dynamics in labor supply, consumption, and wealth; a retirement period that requires the accumulation of retirement saving; a nontrivial demographic structure; and so on.

Finally, while much of the work on heterogeneity in macroeconomics has focused on steadystate analysis, many macroeconomic questions require the analysis of aggregate dynamics. Auerbach and Kotlikoff (1987) showed how to handle a deterministic transition in an overlapping generations setting, and their methodology of iterating on the entire path of prices has proven useful in more general SIM settings. ${ }^{11}$ In an important paper, Krusell and Smith (1998) provided a methodology for analyzing fully fledged SIM models with aggregate shocks. We return to this in Section 5.

Quantitative analysis and calibration The SIM model has become a workhorse of quantitative macroeconomics. Because it combines an explicit micro model of heterogeneous households' behavior with a full-blown equilibrium macro model, both micro data on individual allocations (e.g., earnings, wealth, consumption, and hours worked) and aggregate data from

\footnotetext{
${ }^{10}$ These life-cycle versions of the SIM model owe an intellectual debt to Auerbach and Kotlikoff (1987) who developed a detailed overlapping generations model of the US economy and used it for quantitative analysis (see also Hubbard and Judd, 1986, for an early contribution). These early models, however, did not incorporate uninsurable risk.

${ }^{11}$ One example of such application is the analysis of demographic transitions in the life-cycle version of the SIM model (see e.g. Krueger and Ludwig, 2007).
} 
national accounts are generally used to discipline its parameterization.

A common strategy for parameterization is a mix of "external calibration" using existing parameter estimates (e.g., for preference parameters), and "internal calibration/estimation" where one minimizes the distance between equilibrium moments and their data counterparts, in the spirit of formal structural estimation. Often, the number of target moments is equal to the number of estimated parameters. As argued by Christiano and Eichenbaum (1992) this exact identification strategy allows for a clear separation between what the model is restricted to match and what it is designed to explain. ${ }^{12}$ Browning et al. (1999) discuss some of the difficulties that arise in parameterizing macro models using micro data.

The flexibility of the SIM framework, together with the availability of microeconomic datasets on household behavior and advances in computer power, have allowed model builders to introduce and carefully parameterize more and more sources of heterogeneity, risk, and uncertainty. Section 3 is devoted to this topic.

Efficiency and constrained efficiency How close do agents come to achieving perfect risk sharing in this class of incomplete markets economies? Levine and Zame (2002) show that, with stationary idiosyncratic labor endowment shocks, as agents become increasingly patient, the welfare losses from market incompleteness vanish. Intuitively, as $\beta \rightarrow 1$, the net equilibrium interest rate $r^{*} \rightarrow 0$, and the natural borrowing limit becomes arbitrarily loose. This allows agents to smooth income shocks arbitrarily well.

A related question is whether there exists a set of "deep" constraints on the information or enforcement structure of the environment such that constrained efficient allocations can be decentralized with a risk-free asset, but no state-contingent claims. A positive answer to this question would go a long way toward bridging the gap between the two approaches to market incompleteness ("model what you can see" versus "model what you can microfound") discussed in the Introduction.

Allen (1985) makes some important progress in this respect. He studies Pareto efficient allocations in a two-period model with a pair of information frictions: risk-averse agents can

\footnotetext{
${ }^{12}$ The addition of more moments, if the model is not grossly misspecified, provides extra information on parameter values. However, with more moments than parameters, the issue of how to weight each of the moments arises. For example, the optimal weighting matrix does not perform well in small samples. The exactly identified strategy amounts to a weighting matrix that sets positive and equal weight only on certain moments, based on the investigator's prior about the "first-order" dimensions of the data that the model should fit.
} 
hide their random labor endowment from the planner, and they can also secretly borrow and save. Because they can borrow and lend without being monitored, regardless of the true history, agents always report to the planner the endowment state associated to the largest transfer. As a result, the planner finds it efficient to make the same, history-independent transfer to all individuals at time zero, and to let them do all intertemporal smoothing on their own. It is easy to see that the resulting consumption allocations can be decentralized through a competitive asset market in which agents with the same initial wealth simply trade a risk-free bond. Cole and Kocherlakota (2001) generalize this result to a multiperiod setting, with i.i.d. labor endowment shocks. ${ }^{13}$

Davila et al. (2005) ask how different allocations would look in a SIM world if a utilitarian planner could dictate agents' consumption and savings decisions, while respecting each individual's budget constraint. They find, surprisingly, that the decentralized competitive equilibrium has too little accumulation of capital in aggregate relative to what the planner would choose. The intuition is that the planner (and, ex ante, individual agents) would prefer higher wages and a lower interest rate, in order to induce a redistribution of resources from the capitalincome-dependent rich to the labor-income-dependent poor.

\section{Sources of heterogeneity}

At a broad level, individuals differ in terms of both initial "innate" characteristics and the subsequent shocks they receive over the life cycle. Moreover, these exogenous differences lead to heterogeneity in endogenous choices (e.g., labor supply, human capital accumulation, job search), which either amplify or shrink inequality in economic outcomes.

This view of inequality as a mix of innate characteristics, uninsurable shocks, and endogenous choices raises three important and interrelated questions. First, what is the relative importance of initial endowments as compared to subsequent shocks in determining overall dispersion in economic outcomes? Second, what fraction of changes in inequality over time is due to genuine shocks as opposed to anticipated events for which the individual is prepared? Third, in building microfoundations for a model of individual heterogeneity, where do we draw

\footnotetext{
${ }^{13}$ Abraham and Pavoni (forthcoming) qualify this result: if the hidden information problem is about an action (e.g., unobservable effort) instead of a type (e.g., unobservable endowment), then Pareto efficient allocations are welfare-improving relative to self-insurance. In this sense, the decentralization based only on a risk-free bond is not robust.
} 
the line between exogenous factors beyond the individual's control and rational choices?

We start addressing these questions in the context of earnings and consumption inequality, which is the traditional focus of most of the literature. Next, we examine other sources of inequality which have recently attracted a lot of attention: health shocks, and family shocks.

\subsection{Earnings}

\subsubsection{Shocks versus initial conditions in earnings dynamics}

Shocks The only source of heterogeneity in the early quantitative heterogeneous agents, incomplete markets economies (Imrohoroglu 1989; Huggett 1993; Aiyagari 1994) was exogenous uninsurable idiosyncratic earnings shocks. The ex post heterogeneity in shock histories across ex ante identical individuals translates into consumption and wealth differentials through saving decisions. $^{14}$

This approach places the search for the correct statistical model of earnings shocks at the center of the research agenda. Labor economics has a long tradition of studying income dynamics from longitudinal micro data, such as the US Panel Study of Income Dynamics (PSID). The leading view, based on more than two decades of empirical studies, is that a stochastic process comprising a very persistent autoregressive component and a transitory (or low-order moving average) component accurately describes the data (Lillard and Willis 1978; MaCurdy 1982; Abowd and Card 1989; Meghir and Pistaferri 2004). Recently, macroeconomists have begun to borrow methods developed by this literature to parameterize idiosyncratic earnings risk in their models. A few lessons have been learned.

First, the evidence on rising US earnings dispersion over the last thirty years suggests the existence of substantial time variability in the parameters of the individual earnings process (Gottschalk and Moffitt 1994). This time variability is absolutely central in the literature trying to account for the dynamics of consumption inequality (for the US, see Krueger and Perri 2006, Heathcote et al. 2008b; for the UK, see Blundell and Preston 1998).

Second, in a plausibly calibrated SIM model, transitory earnings shocks are easily smoothed through borrowing and saving, and have a negligible impact on consumption inequality. However, omitting transitory shocks may lead to a severe underestimation of the persistence of the

\footnotetext{
${ }^{14}$ The best-known application of this approach is the quantitative analysis of cross-sectional wealth inequality (Aiyagari 1994; Huggett 1996; Castañeda et al. 2003). See Cagetti and De Nardi (2008) for a survey.
} 
autoregressive (AR) component. In particular, if the true earnings process has both a persistent and a transitory component, but if the postulated model assumes that all shocks are equally persistent, then the estimated AR autocorrelation coefficient will be somewhere between the true values for the persistent and transitory shocks. This explains why some early papers in the literature ascribed low persistence to shocks (e.g., Heaton and Lucas 1996).

For a given unconditional variance of earnings, an $\mathrm{AR}(1)$ with low autocorrelation, say, $\rho=0.80$, has very different implications for equilibrium allocations as compared to, say, a process composed of a unit-root part and a transitory part. In particular, incorporating highly persistent shocks can help explain the hump shape of average consumption over the life cycle, through the precautionary savings of the young (Gourinchas and Parker 2002). Their cumulation over time can generate a growing age profile of consumption inequality (Deaton and Paxson 1994; Storesletten et al. 2004a). Moreover, the more persistent are shocks, the lower will be the equilibrium risk-free interest rate (Huggett 1993) and, under conditions discussed in Section 5, the higher the equity premium (Mankiw 1986).

Third, even with highly persistent earnings shocks, it is notoriously difficult for the baseline SIM model to generate a highly concentrated wealth distribution (see, for example, Huggett 1996). ${ }^{15}$ As noted by Castañeda et al. (2003), the typical strategy of calibrating the exogenous earnings process using panel data is flawed because surveys like the PSID typically undersample the rich and top-code their earnings. They show that one way to replicate the high concentration of wealth observed in the US is to allow for a "rare event" in which individual income productivity becomes extremely high.

Initial conditions In an influential paper, Keane and Wolpin (1997) argued that 90\% of lifetime earnings dispersion is accounted for by factors that are predetermined at the time individuals enter the labor market. This finding, taken at face value, means that macroeconomists must allow for some degree of heterogeneity in initial conditions. More ambitiously, this heterogeneity should be endogenous, and connected to things like family environment and education choices.

The simplest way to introduce these considerations into the standard model is to allow

\footnotetext{
${ }^{15}$ The Survey of Consumer Finances (SCF) reveals that the Gini coefficient for net worth in the US economy is around 0.78. This high degree of wealth inequality is due to extreme concentration at the top: the richest $1 \%$ holds around one-third of the aggregate stock, whereas the bottom half holds only $3 \%$ of it. See Budria et al. (2002) for more details.
} 
the earnings process to have a third component, a fixed individual effect, and to estimate the variance of the fixed effect from panel data. Storesletten et al. (2004a) follow this approach to assess the relative roles of shocks and initial conditions in determining the rise of consumption inequality over the life cycle. In their exercise, fixed effects account for slightly less than half of the cross-sectional variation in lifetime earnings, substantially less than Keane and Wolpin's estimate. The other half is explained by very persistent earnings shocks that cumulate over time.

Since the inception of empirical analysis of income processes, two parallel approaches developed. Besides the pure ARIMA representation, several authors proposed an alternative statistical model that gives heterogeneity in initial conditions a bigger role relative to shocks. This alternative model features cross-sectional heterogeneity in deterministic (linear) log earnings profiles (Lillard and Weiss 1979; Baker 1997; Haider 2001). Heterogeneity in the slope of these profiles could be interpreted as capturing variation in "learning ability." Guvenen (forthcoming) argues that the pure permanent-transitory model is statistically hard to distinguish, in a typical panel dataset, from a model where income profiles are ex ante heterogeneous, and shocks are much less persistent (e.g., with autocorrelation around 0.8). Under this approach, most of life cycle inequality is the result of initial heterogeneity (in the slope of earnings profiles), as in Keane and Wolpin (1997).

One might think that it would be straightforward to discriminate between these two views of earnings dynamics by exploiting evidence on consumption dispersion over the life cycle: while the permanent-transitory model predicts rising consumption dispersion with age, consumption dispersion in the heterogeneous income profile model should level off as soon as agents have accumulated a buffer stock of savings to smooth relatively transitory life cycle shocks (Carroll 1997). Unfortunately, it isn't so easy. First, the consensus view on the facts about consumption dispersion over the life cycle has changed over time. While Deaton and Paxson (1994) document a thirty log point increase in the variance of log nondurable consumption between ages 25 and 65, subsequent authors have estimated much smaller increases. For example, the Heathcote et al. (2005) estimate is growth of only five log points from age 25 to 65 . One important reason for this discrepancy is that Heathcote et al. use a longer sample period, extending beyond the 1980s. Second, the amount of insurance agents can achieve in both models for earnings is sensitive to seemingly minor details of the environment. On the one hand, if shocks are highly 
persistent (say, $\rho=0.85$ ) rather than permanent $(\rho=1)$, then the standard life cycle model features much more consumption insurance over the life cycle (Storesletten et al. 2004a; Kaplan and Violante 2008). On the other hand, if agents gradually learn about their idiosyncratic slope coefficient in a Bayesian fashion, one can generate a sizeable life cycle increase in consumption dispersion in the heterogeneous income profile framework (Guvenen 2007).

Preference heterogeneity represents an alternative way to introduce differences in initial conditions. Historically, macroeconomists have been reluctant to fiddle too much with preferences, because their inherent unobservability puts little discipline on the exercise. However, there are exceptions that have proved fruitful.

Krusell and Smith (1997) suppose that agents differ in their degree of patience, and find that small but persistent dispersion in discount rates can generate large wealth inequality in the cross section.

Heathcote et al. (2007) note that the cross-sectional covariance between individual productivity and hours worked in the US data is negative, while the covariance between consumption and hours is positive. When income effects dominate substitution effects, highly persistent productivity shocks induce a negative sign for both correlations. Now add fixed heterogeneity in the taste for leisure. The covariance between productivity and hours is invariant to preference heterogeneity, but the covariance between consumption and hours is affected positively, since individuals with a strong preference for leisure work less, earn less, and consume less. Enough preference heterogeneity can therefore switch the sign of this latter covariance from negative to positive.

Policy implications Distinguishing between initial conditions and labor market shocks is important, since they have profoundly different policy implications. Insofar as we are interested in designing policies that reduce inequality among households, models emphasizing initial conditions suggest that the intervention should be targeted early in the life of an individual, possibly during childhood, when the key components of learning ability and preferences are malleable. Models based on labor market shocks call for policy interventions that allow unlucky workers to rebuild their skills, or to simply smooth consumption effectively, after a shock. Examples of both types of policies abound in the US economy. 


\subsubsection{Forecastability of earnings dynamics}

Economists have long recognized that agents may have superior information to the econometrician, and that what appears to be a shock to the latter may have been foreseen by the agent. Since an earnings change that was foreseen is likely to have very different implications than a pure shock, one should devise ways to identify how much of earnings dynamics are actually forecastable. But this cannot be done using earnings data in isolation.

According to Blundell et al. (forthcoming), the advance information hypothesis clashes with at least one dimension of the data. With advance information, future earnings growth, say, at date $t+k$ (with $k>0$ ), should be correlated with current consumption growth at date $t$. But this correlation in the data is not significant. The large amount of measurement error in the data, though, makes this a weak test. ${ }^{16}$ An alternative strategy for identifying the predictable component of earnings would be to exploit survey questions, available in some datasets, where households are asked to report a probability distribution over changes in earnings in the next calendar year. Jappelli and Pistaferri (2000) exploit this idea on Italian data.

A growing literature is attempting to use data on a variety of economic choices (labor supply, consumption, education) to separate risk from predictable changes in labor income (Cunha et al. 2005; Guvenen and Smith 2008). To understand the difficulty of the task, consider the exercise carried out by Primiceri and van Rens (forthcoming). They use the permanent income hypothesis to identify as "predictable inequality" the fraction of permanent shocks to earnings that do not translate into inequality in consumption. In similar exercises, however, Blundell et al. (forthcoming) and Heathcote et al. (2007) relax the financial market structure, allowing for additional insurance beyond a risk-free bond, and identify as "insurable" that very same fraction. In other words, the issue of predictability versus shocks is intimately linked to the issue of availability of insurance, which we will discuss in Section 4. More detailed data on private transfers and individual portfolios might help in discriminating between insurability and forecastability.

\footnotetext{
${ }^{16}$ Moreover, this test has no power against the strict (i.e., no learning) heterogeneous income profile model, since all the information is revealed at time zero.
} 


\subsubsection{Microfoundation of earnings dynamics}

The early literature modeled labor income as purely exogenous, but for a number of questions it is important to recognize that individual earnings dynamics have an endogenous component reflecting decisions about labor supply, job search behavior, human capital accumulation, and occupational choice. Therefore, a substantial portion of earnings dispersion may reflect different choices rather than different shocks.

Labor supply Economists have long recognized that women's labor supply is very elastic, since historically they have been the secondary earner in the household. The most recent estimates of males' intertemporal labor supply elasticity converge on values around 0.5 (Domeij and Flodén 2006; Pistaferri 2003).

With an explicit decision of how many hours to supply to the market, uninsurable idiosyncratic risk is transferred from earnings to hourly wages. The way wage uncertainty transmits to earnings, and eventually to consumption, is not trivial and depends on the balance between substitution and income effects, where the presence of income effects reflects market incompleteness.

Permanent (or very persistent) shocks have large income effects, hence hours worked tend to offset the wage shock in the transmission to earnings. Transitory shocks have negligible income effects, and thus flexible labor supply amplifies wage shocks, further increasing the volatility of earnings. Heathcote et al. (2008b) interpret the rise in the cross-sectional wage-hours correlation observed for the US as the result of increasing transitory wage volatility. Moreover, they show that with endogenous labor supply, a rise in transitory (i.e., largely insurable) uncertainty can be welfare improving (see the Box for details).

Job search The standard model assumes competitive labor markets, where individual hourly wages are proportional to individual labor productivity. Search frictions break this connection. Individual wage dynamics become a combination of exogenous productivity shocks at the individual level, and stochastic transitions between employment status, or between jobs, which are, at least in part, choices for the worker. Low et al. (2007) separately identify the two types of labor market uncertainty: productivity versus labor market transitions. They argue that the former induce considerably larger welfare losses, because in addition to being more persistent they are also more exogenous from the worker's perspective. 
Postel-Vinay and Turon (2008) develop a search model where workers can accept or reject job offers, and where earnings are renegotiated between firm and worker when the latter is in danger of being poached by another firm. Interestingly, the model can generate very persistent earnings dynamics, even though the original productivity shocks are uncorrelated over time. This offers a structural microfoundation for commonly used ARIMA-type processes.

Incorporating fully fledged search models of the labor market into equilibrium incomplete markets models is a promising new research avenue. In a model with on-the-job search and exogenous layoffs, Lise (2007) shows that workers who have experienced a long sequence of favorable job offers and sit at the top of the wage ladder have a very strong precautionary saving motive associated to the danger of losing the high wage through a layoff - a mechanism that a symmetric exogenous wage process would not induce. As a result, the model can generate a sizeable degree of wealth concentration.

Human capital Huggett et al. (2006) model earnings dynamics through risky human capital accumulation. Each individual can devote time either to work or to accumulating skills. Uninsurable, idiosyncratic shocks hit the individual-level technology that produces new skills from the time input and the undepreciated stock of past human capital. Individual differences in initial levels of human capital, learning ability, and shock histories translate into inequality in lifetime earnings and consumption. This framework, based on the original Ben-Porath model, offers some microfoundation for statistical models of earnings dynamics with heterogeneous income profiles.

A major challenge in this framework is to identify the process of exogenous shocks, since a wage decline between two periods can be due either to a shock or to a choice to accumulate additional human capital. Huggett at al. exploit the same idea as Heckman et al. (1998): after a certain age, little or no new human capital is produced, hence wage dynamics are entirely determined by shocks. However, self-selection into retirement of those workers with large negative shocks could undermine this approach.

Explicitly modeling the education choice, as opposed to human capital accumulation, has the drawback of abstracting from skill formation during working life, but it has the advantage of being more directly observable. The role of education choices in mitigating risk is clear in the context of the literature on the rise in the US college premium. Consider a model where differentials in educational attainment are represented by fixed individual effects in earnings, 
exogenously distributed in the population. A rise in the college premium corresponds to a rise in the variance of fixed effects, which leads, mechanically, to an ex ante welfare loss (Krueger and Perri 2003). Suppose, instead, that what is exogenously distributed in the population are education costs, and individuals choose whether to become college graduates by comparing costs and returns. A rise in the college premium will induce a fraction of individuals, those with low enough costs, to switch from the low to the high education group. This flexibility can generate welfare gains from a rise in the college premium (Heathcote et al. 2008b).

Self-selection An additional dimension of endogeneity in earnings dynamics is that agents may optimally self-select into groups bearing more or less risk. Consider two recent examples in the literature.

First, it is well known that entrepreneurs have more volatile incomes than workers. Quadrini (2000) develops a model where some agents choose to become entrepreneurs because they have a "project," i.e., a potentially profitable idea. The income stream of the project is riskier than workers' labor income: it can fail, but if successful it can lead to very large payoffs. These two forces induce a subset of agents in the economy (those with entrepreneurial ideas) to save at a higher rate, and a smaller subset of these (the successful) to accumulate large amounts of income and wealth. Cagetti and De Nardi (2006) extend this framework by endogenizing firm size and incorporating borrowing constraints for entrepreneurs. These models can explain the high concentration of net worth observed at the top of the distribution in the US and shed light on the size distribution of firms.

Second, Schulhofer-Wohl (forthcoming) exploits a question about risk tolerance in the Health and Retirement Survey (HRS) to document that less risk-averse individuals are those with the widest earnings fluctuations during their working life, suggesting that preference heterogeneity may be an important factor in occupational choice and risk allocation.

Policy implications A major drawback of the baseline framework, where ex ante identical agents face exogenous earnings shocks, is that policy analysis is very limited. Only the (ex post) lucky become rich, and only the (ex post) unlucky become poor. Any redistributive flat or progressive labor income tax is welfare-improving. Ex ante welfare would be maximized by taxing away all individual earnings and redistributing them lump-sum.

The additional microfoundations discussed in this section establish a well-defined fiscal 
policy trade-off. Besides the usual welfare gain from redistribution, there are new welfare losses. Taxes distort the efficient choices for hours worked, on-the-job search effort, college enrollment, selection into self-employment, and so on. Overall, the consequences of fiscal policies in these models become rich and complex, with some agents losing and others gaining, as we would expect in actual economies.

\subsection{Beyond earnings: additional sources of risks}

Health shocks Modeling health shocks is a more complex task than modeling productivity shocks, because health status potentially impacts the agent's utility function, in addition to her budget constraint.

The impact of health shocks on preferences is twofold. First, a worsening of health status translates into an increase in mortality rates. This is important because survival probabilities affect discounting, and hence saving and human capital accumulation. Second, it is plausible that an individual in bad health would not derive the same utility from many types of (nonmedical) consumption expenditures. Palumbo (1999) estimates that a negative health shock significantly reduces the marginal utility of nonmedical consumption.

Health has a large impact on earnings. Based on the Medical Expenditure Panel Survey (MEPS), Attanasio et al. (2008) find that individuals who report a deterioration of (subjective) health status from "good" to "bad" experience an average fall in hourly wages of $15 \%$.At the same time, health shocks induce households to purchase insurance and a range of medical goods and services. A common approach has been to treat medical spending (like earnings) as exogenous, and to estimate a stochastic process for expenditure shocks. French and Jones (2004) fit a statistical model comprising persistent and transitory components as well as a low-probability catastrophic event: with probability $0.1 \%$ per year, households are hit by an expenditure shock beyond $\$ 100,000$ in present value.

Enriching incomplete markets models by introducing health shocks is important for at least three reasons. First, modeling health shocks allows one to address the issue of how well private markets and current institutions (e.g., Medicare and Medicaid) function in insuring households. Second, uncertainty about health status is a key driving force for the saving decisions of the elderly (Palumbo 1999; De Nardi et al. 2006). Third, a nontrivial probability of receiving large expenditure shocks after retirement could explain why annuity markets are so thin: they are 
not effective in providing financial security (Sinclair and Smetters 2004).

Finally, the role of initial conditions and endogeneity are as relevant for health inequality as for earnings inequality. Case et al. (2002) find that poor families spend little on their children's health, and that poor initial health conditions persist into adulthood. Moreover, individuals make more or less healthy choices (with respect to diet, smoking habits, exercise, etc.) throughout their life. Therefore, health status is best modeled as an endogenous stock that depreciates stochastically over time, with individuals deciding how much to invest every period. The main challenge is how to parameterize this technology.

Families as shocks For many people, the biggest events in life involve changes in family composition: marriage, divorce, the birth of children, the death of a parent or spouse. Many of these events have an important exogenous component, and as such represent an important source of risk. Cubeddu and Ríos-Rull (2003) embed marital status risk in an incomplete markets model and conclude that this type of risk is a larger source of precautionary saving than earnings risk. At the same time, as we will discuss in the next section, the family is an important source of insurance, since individuals are altruistically connected to their parents, siblings, spouses, and children. Young children depend heavily on their parents, a nonworking spouse on his or her partner, an elderly widow on her adult offspring.

Clearly, while events such as marriage, divorce, and fertility contain an exogenous component (risk), they also involve some decision making. Models with a component of endogenous choice are required to study the effects of policies such as divorce laws or welfare assistance to children of single-headed families (e.g., Aiyagari et al. 2000).

Shocks to capital In most incomplete markets models, shocks to labor productivity are the only source of idiosyncratic income risk. In reality, there is also substantial variation in the return to capital, which for public equity shows up as cross-sectional variation in stock returns. However, traded stocks are easily diversified. Private equity is where idiosyncratic capital income risk really matters for risk sharing, since here it translates directly into income risk for the self-employed. Quadrini (2000) pioneered the quantitative study of this source of risk. In Angeletos and Calvet (2006) each agent is an entrepreneur and faces idiosyncratic risk in private production and investment. They show that a private equity risk premium works to reduce the aggregate capital stock, offsetting the familiar positive precautionary saving effect. 
Housing represents another important source of capital income risk, since housing is a major component of households' portfolios, and house prices have a large idiosyncratic component associated to geographical location (Davis and Heathcote, 2007). This risk is not easily diversified by spreading ownership across a range of properties because rental markets function poorly.

In general, capital income risk remains relatively underexplored within this class of models.

Correlation among sources of risk Finally, it is important to recognize that all these shocks can be correlated. For example, a job displacement can put family relations under strain and lead to a divorce. A deterioration in health status, such as a long illness or a disability, can induce a permanent loss in earnings. A decline in labor demand in a specific geographical area (e.g., a plant closing) can trigger a fall in local housing prices, creating a comovement between individual shocks to earnings and shocks to wealth.

These considerations suggest that a multivariate system, with nonzero cross-correlations among shocks, may be the appropriate statistical model to capture the various sources of idiosyncratic risk faced by households.

\section{Channels of insurance}

What are individuals' key channels of insurance against the risks described in the previous section? At one extreme, as we discussed in the Introduction, one could assume complete markets against idiosyncratic risk. However, while this is a useful theoretical benchmark, it is soundly rejected by the data. The earliest versions of the standard incomplete markets model incorporated just one insurance vehicle: risk-free saving. As we will now describe, this view of insurance is too limited, since it abstracts from a range of other channels that allow individuals to pool risks. Thus, the truth is somewhere in between the economy with a complete set of state-contingent claims, and the economy with a single bond. In this section we focus on the insurance-providing roles of (1) financial markets, (2) labor supply decisions, (3) the family, and (4) the government. ${ }^{17}$

\footnotetext{
${ }^{17}$ We will not discuss the role of insurance provided by firms to their employees, which has yet to attract much quantitative theoretical work. Guiso et al. (2005) estimate that Italian firms provide their workers with considerable insurance against shocks to firm performance, especially when such shocks are transitory.
} 


\subsection{Financial markets}

The early heterogeneous agents macro literature built on the classic income fluctuation problem, in which agents use risk-free saving and borrowing to smooth consumption in the face of shocks to income. It was quickly recognized that the extent of insurance agents could achieve using risk-free assets would depend critically on the size and persistence of shocks (see Section 3), the net supply of assets available for smoothing, and the extent of borrowing permitted. In fact, these last two are flip sides of the same coin, because what ultimately determines individuals' ability to smooth consumption is how far they are from the borrowing constraint. Thus, giving all agents an extra dollar of wealth or loosening the borrowing constraint by a dollar has very similar effects on allocations (see Proposition 1 in Ljungqvist and Sargent 2004, for a formal discussion).

In Bewley (1983) agents were completely prevented from borrowing. At the other extreme, Aiyagari (1994) required only that they were able to repay debts with probability one - the "natural" borrowing limit. Zhang (1997) gave borrowers the option to default on debt, making willingness to pay rather than ability to pay central to the determination of borrowing limits. In his model, when contemplating default, borrowers expect to be punished by suffering permanent exclusion from financial markets. Default does not occur in equilibrium, because borrowing limits are tight enough to ensure that agents at least weakly prefer to repay debts in every possible future state. An important feature of these "endogenous" borrowing constraints is that their position is sensitive to changes in other details of the environment: for example if shocks become larger, incentives to maintain access to credit in order to smooth consumption will be strengthened, and thus it should be possible to support more borrowing in equilibrium.

In reality, of course, default is an option, and potentially an important one from the perspective of self-insurance, since it allows borrowers to make the amount of debt they repay a function of the shocks that hit them. For example, one could envision choosing to default on debts in the event of a job loss or a large unanticipated medical expense, and repaying otherwise. The cost to households of defaulting on debts depends on the extent to which they are subsequently able to protect themselves from creditors and to regain access to credit markets, which in turn depend in large part on the details of bankruptcy law.

Several papers, beginning with Athreya (2002), develop quantitative extensions of the standard incomplete markets model to allow for default. In Livshits et al. (2007) and Chatterjee 
et al. (2007) lenders offer a menu of loan contracts, one for each level of borrowing, such that larger loans come with higher interest rates to reflect increased probability of default. These models allow one to explore the welfare implications of alternative bankruptcy laws. An important general result here is that policymakers face a trade-off. On the one hand, treating bankrupts more harshly makes self-insurance via precautionary saving easier in equilibrium, since stronger incentives to repay debts lower default-risk premia and thus the cost of borrowing. On the other hand, as bankruptcy becomes more costly, debtors become less likely to exercise this option: in the limit, debt is effectively noncontingent.

In addition to the literature on unsecured credit, there is a parallel literature on the role of housing and secured credit (mortgages) as a source of both risk and insurance. FernandezVillaverde and Krueger (2002) examine the quantitative impact for consumption and saving behavior of incorporating durables (mostly housing) in an incomplete markets life cycle model. In models of this sort, housing tends to hinder consumption smoothing early in the life cycle, since individuals want to buy a house (owning is preferred to renting), but home buying typically requires a down payment, which leaves home buyers liquidity constrained. At the same time, like any other asset, housing wealth is also a vehicle for self-insurance. Venti and Wise (2001) find that older home owners sometimes reduce home equity in response to shocks to family status, like entry to a nursing home or the death of a spouse.

However, home equity is rarely used to finance general consumption in retirement, which has spurred a debate on whether it should be included in measures of household net worth. This question is important, because incomplete markets models are typically calibrated to replicate the empirical wealth to income ratio, and thus what counts as wealth impacts the extent of equilibrium self-insurance.

Beyond housing and risk-free savings, other important components of household wealth include private pensions, social security, and public and private equity. The quantitative macrofinance literature generates predictions for optimal portfolio diversification given the nature of the risk individuals face - for example, how individuals should adjust the equity-bond mix as they move through the life cycle (see Section 5). A general finding is that in a model with heterogeneous agents, individuals will choose to hold different portfolios, such that risk sharing is effectively improved. For example, risky equity will be disproportionately held by individuals who either face little idiosyncratic risk, or have relatively high tolerance for risk, or receive 
non-asset income that co-moves negatively with the stock market. ${ }^{18}$ Empirically, however, investors appear to invest in stocks that co-move closely with their nonfinancial income (Massa and Simonov 2006), which poses a puzzle. Chien et al. (2008) is a recent example of a model economy populated by traders who are heterogeneous in the degree of sophistication with which they hedge their labor income risk.

The recent trend toward easier access to credit suggests that households are now better placed to use financial markets to insure against idiosyncratic shocks. For example, it is now easier to use credit cards and home equity loans or lines of credit to smooth idiosyncratic income shocks. At the same time, however, financial market innovation may have left the economy more susceptible to aggregate shocks. In the late 2000s, declining house prices left many Americans with negative home equity, spurring a wave of mortgage defaults and a general credit crunch. Developing a better understanding of the relationship between access to credit at the individual level and the response of the economy to aggregate shocks is a priority for future work (see Chambers et al. 2008 or Kiyotaki et al. 2007).

Finally, the insurance industry offers explicit insurance against certain types of idiosyncratic risk (e.g., property risks, health, disability, uncertain longevity, death of a spouse). Surprisingly little work has been done on attempting to quantify the value of insurance provided by these markets. Exceptions include a small literature on the interaction between social security and private annuity and life insurance markets (Hong and Ríos-Rull 2007 and Hosseini 2008 are recent examples) and on the impact of tax subsidies to employer-based health insurance (Jeske and Kitao 2007).

\subsection{Insurance from labor supply}

Individuals' labor market choices present a range of insurance opportunities. The simplest example is that individuals can adjust hours in response to fluctuations in their wages. As with any margin of adjustment, endowing agents with the ability to adjust hours must make them at least weakly better off. Papers exploring the insurance value of hours flexibility, and the interaction between flexible labor supply and precautionary savings, include Low (2005), Flodén (2006), Pijoan-Mas (2006), and Marcet et al. (2007). Heathcote et al. (2007) describe

\footnotetext{
${ }^{18}$ Note, however, that theoretically it is only in the limit, when markets are almost complete, that introducing additional assets is guaranteed to improve risk sharing and welfare.
} 
a tractable environment in which optimal labor supply can be characterized in closed form. These expressions clarify that individuals will optimally increase hours in response to positive idiosyncratic shocks that can be directly insured via financial markets, but will tend to adjust hours inversely in response to wage shocks that would otherwise translate one for one into consumption.

In reality, workers need not passively accept the wage they are offered in their current job. The search-matching literature has long emphasized the importance of endogenizing choices to form and dissolve matches, as well as the choice of search intensity. A few recent papers integrate these sorts of models within the SIM framework (see Krusell et al. 2007, Lise 2007). Kambourov and Manovski (forthcoming) emphasize the importance of changing occupations in response to occupation-specific productivity shocks, while Hassler et al. (2005) focus on changing geographic region in response to unemployment and location-specific shocks.

\subsection{Insurance within the family}

The lion's share of work on quantitative heterogeneous agent models have focused on the "bachelor household" - one breadwinner per household. While this approach has offered many valuable insights, it is clear that abstracting from multi-member families misses a potentially important source of insurance. Moreover, extending the standard incomplete markets environment to incorporate an explicit model of the household allows for a more natural mapping between data and model: individual-level data on earnings and hours and household-level data on consumption and wealth can be directly compared to their model counterparts.

Attanasio et al. (2005) argue that the ability of wives to adjust labor market participation decisions offers valuable insurance against shocks to their husbands' earnings. The potential for this type of insurance has risen over time with the narrowing of the gender wage gap (Heathcote et al. 2008b). However, more work is required to uncover the joint process for husband and wife labor market risk, a task complicated by the fact that market wages are not observed for spouses who specialize in home production.

Intergenerational transfers in the form of investment of parental time and money in child care and education are very large and offer a degree of insurance against the risk that children are unlucky in their draw for initial conditions (see Mulligan 1997 for a comprehensive review). Fogli (2004) notes that in countries with poorly developed credit markets and rigid labor markets, 
a higher fraction of young people tend to live at home, suggesting that insurance within the family can substitute for self-insurance through financial markets. Similarly, Kaplan (2007) argues that for young workers, the option to transit between living independently and living with parents is an important channel of insurance against labor market risk.

Of course, a critical issue for quantifying the extent of within-family insurance is to understand how other family members enter into individual preferences. There is as yet no consensus on what is the right way to model the family, and how much insurance is provided within that model. Many macro models adopt the unitary model of the household (e.g., Regalia and Ríos-Rull 2001, Attanasio et al. 2005, Heathcote et al. 2008b). The unitary model assumes that family members share the same preferences and collaborate to maximize aggregate family utility. Thus, all individual risks that are imperfectly correlated across family members are pooled. In response to shocks, family members reallocate time devoted to market work, home production and leisure, and conduct monetary or in-kind transfers within the family.

However, various implications of the unitary model have been tested empirically and typically rejected (see, for example, Bourguignon et al. 1993). Lise and Seitz (forthcoming) estimate a collective model of the household and find large differences in consumption between husbands and wives. Most collective models of the family are static in nature, and although these models endow family members with heterogeneous preferences, they require that allocations within the family be Pareto optimal. In a dynamic model, Pareto efficiency implies that idiosyncratic risks within the family realized after family formation end up perfectly insured. However, Mazzocco (2007) tests and rejects the hypothesis of intra-household commitment, suggesting that ex ante efficiency in marriage is too much to hope for.

Several other modeling routes have been explored. Two pioneering papers that model noncooperative intra-family interaction are Aiyagari et al. (2000) and Nishiyama (2002). Another way to model husband and wife interaction is to require that allocations maximize risk sharing, subject to neither spouse wanting to terminate the relationship. Ligon (2002) builds a dynamic model in which threat points - and thus Pareto weights - evolve over time, and characterizes ex post efficient allocations. Finally, Greenwood et al. (2003) build a model that allows for marital dissolution, though their model has limited dynamics. We expect more quantitative work in this area. 


\subsection{Public insurance}

On top of insurance provided privately through markets and the family, the government provides important additional risk sharing via redistributive taxation and various social insurance programs. There is a vast quantitative literature exploring the welfare implications of alternative public policies, beginning with Auerbach and Kotlikoff (1987). Aiyagari and McGrattan (1998) explored how government debt expands the net supply of assets available for self-insurance. Imrohoroglu et al. (1995), Conesa and Krueger (1999), Storesletten et al. (1999), Huggett and Ventura (1999) and Huggett and Parra (2008) examine the role of social security as a partial insurance and redistribution device. Flodén (2001) explores the interaction between debt and public transfers. Domeij and Heathcote (2004) and Nishiyama and Smetters (2005) consider the distributional impacts of changing the balance between taxation of labor, capital, and consumption. Conesa and Krueger (2006) and Conesa et al. (forthcoming) investigate the tradeoff between efficiency and insurance associated with progressive taxation. Hansen and Imrohoroglu (1992), Low et al. (2007) and Lentz (forthcoming) conduct quantitative explorations of unemployment insurance.

Perhaps the most important government program from a redistributional perspective is public education, which constitutes a sizeable transfer to children from poorer families (Fernandez and Rogerson 2003). Public health care programs are another important equalizing force. In the United States, Medicaid is explicitly means-tested and partially covers medical costs for low-income households. Medicare is larger than Medicaid in terms of budget, but its progressivity is still debated: whereas high-income individuals pay higher Medicare taxes, they also receive more benefits as retirees because of their longer life expectancy (McClellan and Skinner 2006).

To what extent does public insurance crowd out private insurance? Hubbard et al. (1995) showed that means-tested social insurance programs provide disincentives to accumulate precautionary savings and thus reduce self-insurance. Attanasio and Ríos-Rull (2000) and Krueger and Perri (2005) explore environments with enforcement frictions in which public tax and transfer policies reduce the scope for private insurance within the family or through financial markets by weakening repayment incentives.

Quantifying insurance Two central themes of this review are that while households 
face many sources of risk, they also enjoy access to many different forms of insurance. The papers discussed above generally adopt the strategy of building models that incorporate the key sources of risk for the question of interest, and then modeling explicitly what are likely to be the most important avenues of insurance. One way to evaluate such models is to ask whether they deliver the right amount of insurance overall. Kaplan and Violante (2008) argue that the baseline SIM model has somewhat less consumption insurance against permanent shocks than is suggested by micro data. Heathcote et al. (2008b) build a richer version of the SIM model in which individuals can insure against shocks to labor productivity via a range of mechanisms. In addition to risk-free savings, the model incorporates flexible labor supply, human capital investment, transfers between husband and wife, and social security. They argue that this model is broadly consistent with the evolution of cross-sectional inequality in consumption and hours, both over the life cycle and over time.

An alternative strategy is to be more agnostic about the details of specific insurance mechanisms, and to combine minimal model structure with panel data on earnings, consumption, and hours in order to quantify the fraction of total risk that households appear to be insuring in practice. This approach is followed by Blundell et al. (forthcoming) and Heathcote et al. (2007).

\section{$5 \quad$ Heterogeneity and the aggregate economy}

Our third theme is the impact of individual-level risk on the aggregate economy. We begin by arguing that changes in the magnitude and the nature (i.e., insurability) of idiosyncratic uncertainty can have large effects on average quantities and on prices. Next, we introduce aggregate risk into the SIM model, and we examine some important methodological issues that arise. Finally, we study how the answer to some classic questions pertaining to the aggregate economy - initially studied within representative agent models - change once analyzed within the SIM model. We examine the welfare costs of business cycles and inflation, as well as asset pricing.

\subsection{Impact of microeconomic uncertainty on aggregate levels}

Consider first the saving decision. SIM models with exogenous earnings predict that higher earnings risk triggers larger precautionary savings and, hence, a higher capital stock. As a 
result, in equilibrium, the interest rate is lower, the wage rate is higher, and average output per hour worked (labor productivity) increases (Aiyagari 1994).

More surprising, perhaps, is that heterogeneity can also affect average labor productivity through labor supply. To see this, consider a model with endogenous labor supply, where agents are subject to exogenous fluctuations in their efficiency units of labor. The labor market is competitive, so individual wages reflect individual productivity. Suppose that there are two orthogonal sources of wage risk, one purely transitory (hence insurable) and one permanent (hence hard to insure).

When most of the risk is transitory, individuals with relatively high wage draws will work relatively long hours, and thus aggregate labor productivity will be high. This effect is stronger the higher is the Frisch elasticity of labor supply, and the larger is the insurable fraction of wage dispersion. Conversely, suppose that most of the risk is permanent. Now, if wealth effects are strong enough, individuals who experience a wage rate reduction will increase their hours worked in order to mitigate the fall in consumption, which implies that aggregate labor productivity will fall. Heathcote et al. (2008a) illustrate how this mechanism affects the welfare analysis of labor market risk. For details, see the enclosed Box.

\section{BOX: THE WELFARE ANALYSIS OF LABOR MARKET RISK WITH FLEXIBLE LABOR SUPPLY}

What are the welfare implications of wage risk? On the one hand, greater wage volatility makes incomplete insurance more costly. On the other, it offers opportunities to increase productivity by working harder when wages are higher. Heathcote et al. (2008a) analyze an economy in which there is perfect insurance against transitory wage shocks, but permanent shocks cannot be insured directly. They study the welfare gain from completing markets against idiosyncratic risk (i.e., fully insuring permanent shocks to wages).

With Cobb-Douglas preferences, completing markets generates two positive welfare effects (expressed as permanent percentage changes in consumption): (i) a gain of $\gamma v / 2$ from eliminating the variance $v$ of permanent risk, where $\gamma$ is the coefficient of relative risk aversion, and (ii) a further gain of $\sigma v / 2$ from increasing by the same amount $v$ the variance of insurable risk, where $\sigma$ is workers' Frisch elasticity of labor supply. The first expression is analogous to Lucas 
(1987), though here it applies to (large) idiosyncratic risk, rather than (small) aggregate risk. The second expression is new and reflects the fact that insurable wage risk is welfare-improving with flexible labor supply. Surprisingly, a plausible calibration implies that most of the welfare gains can be attributed to higher aggregate productivity rather than reduced inequality.

\section{$5.2 \quad$ Krusell and Smith (1998)}

Computational complexity In all dynamic, rational expectation models, agents must form (rational) forecasts of future prices in order to optimize behavior. In a representative agent economy, equilibrium prices depend on a handful of aggregate state variables, and this problem is relatively simple to solve. However, once aggregation is abandoned, market-clearing prices become a function of the entire distribution of agents (see Ríos-Rull 1995). Forecasting prices now requires a law of motion for the distribution. But literally including the distribution (an infinite-dimensional mathematical object) among the state variables when solving the numerical problem is not feasible. ${ }^{19}$

An important breakthrough came when Krusell and Smith (1997, 1998) proposed to approximate the numerical optimization problem by assuming a form of near-rational behavior: agents view prices as evolving only as functions of a finite set of moments of the distribution (e.g., its mean and variance), and they optimize given a forecasting rule that depends only on these moments. Krusell and Smith describe an iterative procedure for computing the forecasterror-minimizing coefficients for this rule. Agents are near rational in the sense that when they optimize given the forecasting rule, errors for market-clearing prices turn out to be very small ex post.

This methodology greatly extends the range of questions that can be studied within this class of models and creates a rich environment to analyze the interaction between idiosyncratic and aggregate risk. However, a caveat remains. Even if the economy evolves very nearly as

\footnotetext{
${ }^{19}$ In order to sidestep this issue, early work either examined aggregate fluctuations in economies with fixed interest rates (Imrohoroglu 1989) or assumed the existence of a monetary authority setting a "policy rule" for the interest rate as a function only of the exogenous aggregate states (Díaz-Giménez et al. 1992).

Subsequent contributions addressed the problem by keeping the number of different types low. Telmer (1993) and Lucas (1994) solved a class of models with only two types of agents, thereby minimizing the "curse of dimensionality." Ríos-Rull (1994) instead proposed a set of linear quadratic approximations in overlapping generations models with heterogeneity across generations but no within-cohort inequality.
} 
expected when agents take as given a low dimensional forecasting rule, there is no guarantee that its aggregate dynamics are close to those in the true rational expectations equilibrium. Krusell and Smith suggest experimenting with adding additional moments to the forecasting rule to ensure that, locally at least, aggregate dynamics are not sensitive to expanding agents' information sets. ${ }^{20}$

Approximate aggregation Recall that in the neoclassical growth model with complete markets, one obtains perfect aggregation because, with homothetic preferences, Engel curves (consumption functions of wealth) are linear (Chatterjee 1994). In SIM models, instead, consumption decision rules are generally concave in wealth (Deaton 1991), so aggregate consumption will depend on the distribution of wealth, and perfect aggregation will fail. However, Krusell and Smith and subsequent users of their methodology have found that even though SIM economies do not perfectly aggregate in theory, these models often deliver "approximate aggregation" in practice. Krusell and Smith coined this term to label their key result that "in equilibrium all aggregate variables $[. .$.$] can be almost perfectly described as a function of two$ simple statistics: the mean of the wealth distribution and the aggregate productivity shock."

In addition, Krusell and Smith also document that the aggregate simulated time series from their incomplete markets model are almost indistinguishable from those generated by a representative agent economy with identical preferences. However, one should not assume that there always exists a representative agent economy that produces the same aggregate dynamics as the incomplete markets economy. This is an important difference with respect to complete markets environments, where exact aggregation and existence of a representative agent go hand in hand. An example that illustrates this point is Heathcote (2005), who considers lump-sum changes in the timing of taxes in a SIM model. He finds that approximate aggregation holds in the Krusell-Smith sense (the state variables are aggregate capital, aggregate government debt, and the current tax level). At the same time, however, changes in the timing of taxes turn out to have large real effects - effects that would be absent in any representative agent economy, where Ricardian equivalence holds.

\footnotetext{
${ }^{20}$ Krusell and Smith (1998) and virtually every other "user" of their methodology directly pose a recursive formulation of the problem, with the distribution as a state. Recently, Miao (2006) established equivalence between the recursive and sequential competitive equilibrium when the state space includes, in addition to the distribution, the individual expected continuation values. But existence of a recursive equilibrium defined without this latter state variable, and its relation with the sequential formulation, are still open questions.
} 
What are the limitations of the Krusell-Smith approach? Clearly, if aggregate shocks were to systematically redistribute wealth across agents with different propensities to consume out of wealth, then a low dimensional forecasting rule could fail. Thus approximate aggregation is more likely to hold, the closer to linear are consumption decision rules and the smaller is the effect of aggregate shocks on wealth inequality. Small technology shocks - considered by Krusell and Smith - do not change the wealth distribution much, while big shocks to taxes or asset prices could have large effects. ${ }^{21}$

\subsection{Welfare costs of business cycles and inflation}

Costs of business cycles Lucas (1987) showed that, in a representative agent framework, the welfare gain from removing purely transitory fluctuations in aggregate consumption (relative to a trend) is remarkably small-less than one-tenth of a percent of lifetime consumption for standard preferences (i.e., a coefficient of risk aversion between, say, one and five). However, given the concern for business cycles among politicians and the general public, Lucas' finding has been viewed as a puzzle. Does introducing idiosyncratic risk change the answer to Lucas' question?

As a first pass, suppose that individual risk and aggregate risk are independent and maintain Lucas' assumption that aggregate shocks are transitory. Then, with CRRA preferences, it is easy to show that idiosyncratic risk has no influence on the cost of aggregate risk (Constantinides and Duffie 1996; De Santis 2007). Mechanically, there are two ways to change the joint stochastic process for aggregate and idiosyncratic shocks to generate larger numbers than Lucas for the cost of aggregate fluctuations.

The first is to maintain transitory aggregate shocks, but to assume that the variance of persistent idiosyncratic shocks is positively correlated with the realization of the aggregate shock. Storesletten et al. (2004b) offer some evidence that in PSID data the variance of persistent earnings shocks is substantially higher in recessions than in expansions. This mechanism amplifies the cost of business cycles, because the worst idiosyncratic shocks tend to occur when aggregate times are already bad. ${ }^{22}$

\footnotetext{
${ }^{21}$ Huggett (1997) illustrates that a large wealth redistribution affects aggregate consumption in SIM environments. Krueger and Kubler (2004) consider overlapping-generations economies with aggregate shocks to productivity and depreciation rates and a large but finite number of agents $(<30)$. They find that approximate aggregation holds only when depreciation rates are deterministic, i.e., in cases without large shocks to wealth.

${ }^{22}$ Imrohoroglu (1989) also explores cyclical variation in idiosyncratic risk, but her focus is on unemployment
} 
The second is to maintain that the assumption that the variance of idiosyncratic shocks is uncorrelated with the cycle, but to assume that both idiosyncratic and aggregate shocks are permanent. ${ }^{23}$ Since both individual and average consumption appear highly persistent in practice, this seems a reasonable thought experiment, even if it is not the experiment Lucas originally had in mind. In this case, De Santis (2007) illustrates that aggregate fluctuations are more costly in welfare terms when there are idiosyncratic fluctuations in the background. This result reflects the fact that lifetime utility declines increasingly quickly as one increases the variance of permanent shocks and thus the growth rate of within-cohort consumption dispersion. This convexity in lifetime utility means that the welfare gain from a marginal reduction in permanent risk (whether aggregate or idiosyncratic in nature) is increasing in the initial variance of permanent shocks. An important caveat is that De Santis assumes an infinite horizon setting. The gains would be substantially smaller in a finite life cycle model, because then consumption inequality would not grow without bound.

To tackle the cost of business cycles question in an incomplete markets environment requires describing a process for idiosyncratic risk in the counterfactual aggregate-risk-free economy. However, existing models lack unifying microfoundations for aggregate and idiosyncratic risk, and thus offer little guidance on the right way to proceed. Different statistical assumptions will lead to different results. Storesletten et al. (2001) and others propose setting the variance of earnings risk, in the counterfactual economy, equal to the unconditional variance of individual earnings, averaged across business cycles. The welfare effects become much larger if one assumes that removing business cycles would effectively reduce individual risk. Applying the "integration principle" proposed by Krusell and Smith (1999), Krebs (2003, 2007) holds constant the average standard deviation of (permanent) earnings shocks across experiments. Due to Jensen's inequality, this amounts to assuming that the unconditional variance of income risk is smaller in the absence of aggregate fluctuations. With CRRA utility the welfare cost of fluctuations is approximately linear in the variance of log consumption. Accordingly, Krebs finds large welfare gains from removing business cycles.

In a heterogeneous agents economy, one should expect cross-sectional differences in the

risk, rather than earnings risk as in Storesletten et al. (2001). She finds gains from removing business cycles only slightly larger than Lucas (1987), in part because unemployment spells are typically short in the US economy, and thus relatively easy to smooth with savings.

${ }^{23}$ This idea is taken even further in the new literature on long-run risk, where the growth rate of consumption has a persistent component (Bansal and Yaron 2004). 
gains from eliminating aggregate fluctuations. Krusell et al. (forthcoming) find that this heterogeneity is quantitatively large: low-wealth agents enjoy a utility gain of up to $4 \%$ of lifetime consumption. This result echoes the finding of Storesletten et al. (2001), who report the largest gains in their OLG economy for young households.

Empirically, incomes in the bottom half of the population fluctuate more over the business cycle (Kydland 1984; Ríos-Rull 1993), partly because unemployment is concentrated among low-skilled and low-income workers. The welfare implications of aggregate risk in models where business cycles affect certain types of workers differently have yet to be fully explored.

Costs of inflation There is a related literature on the welfare cost of inflation. Inflation has potentially large distributional consequences. First, the poor hold a larger share of their wealth in cash than the rich, and are therefore more vulnerable to high (expected) inflation. Erosa and Ventura (2002) demonstrate this effect using a monetary growth model extended to feature incomplete markets and individual heterogeneity. At the aggregate level, their model economy operates similarly to standard representative agent monetary models. However, the burden of inflation is disproportionately borne by the poor, in the form of a lower average return on their savings (see also Imrohoroglu 1992; Albanesi 2007).

Second, an unexpected increase in inflation will redistribute wealth away from those with disproportionately large nominal asset positions. Doepke and Schneider (2006) quantify this effect empirically. They find that a surprise increase in inflation would induce large welfare costs on old, rich individuals, who are the major bondholders in the economy.

Surprisingly, the study of monetary policy in macroeconomics has largely bypassed the SIM model. Díaz-Giménez et al. (1992) is an early example within the SIM framework which received very limited follow-up.

\subsection{Asset pricing}

In a seminal paper, Mehra and Prescott (1985) showed that with three key assumptions (1) complete markets, (2) no trading frictions, and (3) time-additive utility, agents must be extremely risk-averse in order for the stochastic growth model to deliver the empirical average excess return on stocks relative to bonds. This is the "equity-premium puzzle." 24

\footnotetext{
${ }^{24}$ To account for historical US data, a risk aversion larger than, say, 50 would be required. In comparison, micro estimates of risk aversion fall in the range $1-5$, which is generally viewed as the "plausible" range.
} 
The key source of the puzzle is that fluctuations in aggregate consumption growth in the model are too small. Relaxing the assumption of full insurance against individual income risk appears promising because it will generate large fluctuations in individual consumption growth, while leaving aggregate consumption growth unaffected.

Suppose, first, that individual heterogeneity and aggregate risk are independent. In this case, individual risk turns out to be irrelevant for the price of aggregate risk (Mankiw 1986; Telmer 1993; Heaton and Lucas 1996; Krusell and Smith 1997). Constantinides and Duffie (1996) show this formally in an example with unit-root individual earnings risk, and Krueger and Lustig (2006) extend this result to a more general set of income processes and trading frictions.

Suppose now that idiosyncratic risk varies systematically with aggregate consumption. Mankiw (1986) shows that when preferences exhibit a precautionary motive, the equity premium will increase if the dispersion in uninsurable earnings shocks is countercyclical. Focusing on CRRA utility and unit-root earnings shocks, Constantinides and Duffie (1996) solve for the equity premium in closed form, confirming Mankiw's result. Storesletten et al. (2007) calibrate an overlapping generations model to quantify the magnitude of this effect. Using empirical estimates of countercyclical income risk, they find that individual risk can account for up to one-quarter of the empirical equity premium. ${ }^{25}$

An alternative mechanism for heterogeneity to influence asset prices is if aggregate risk is concentrated in fewer hands. Clearly, if only a subset of the population hold risky assets, then their consumption growth will be both volatile and highly correlated with the equity return. Empirically, stock owners' consumption covaries more closely with the stock market than the consumption of individuals who do not participate in equity markets (Attanasio et al. 2002; Brav et al. 2002; Vissing-Jørgensen 2002) ${ }^{26}$ This will increase the premium required (by the stockholders) to continue to hold stocks.

To investigate the importance of this channel, Guvenen (2006) examines a heterogeneous agents real business cycle model where a small minority of agents (20\%) are allowed to hold stocks, and where these investors have a high intertemporal elasticity of substitution (EIS). The remaining agents can only save in a bond and have a lower EIS. Guvenen finds that a plausibly

\footnotetext{
${ }^{25}$ Their model also replicates the fact that the share of financial wealth in stocks is increasing with age.

${ }^{26}$ Entrepreneurial risk - which due to financial frictions cannot be diversified in financial markets - is an alternative channel by which aggregate risk is concentrated in fewer hands; see Heaton and Lucas (2000).
} 
calibrated version of this model can account remarkably well for both the equity premium and a number of additional key financial statistics, such as the Sharpe ratio and the covariance between the return on equity and the risk-free rate.

Due to a low EIS, the investors who are forced to hold bonds are more interested in smoothing consumption. Hence, in recessions (booms) the non-stockholders want to reduce (accumulate) wealth. This wealth must be picked up by the stockholders, further adding to the pro-cyclical variation in their consumption growth, and therefore increasing the premium they require to hold stocks.

The main critiques against explanations for the equity premium based on limited stockmarket participation are two. First, the implied concentration of aggregate risk on stockholders is difficult to detect empirically. Second, it would be preferable to endogenize non-participation. In fact, it turns out that the non-participants in Guvenen's model would be willing to pay substantial amounts to gain access to equity markets. Models with transaction costs to hold stocks (as pioneered by Aiyagari and Gertler 1991) allow one to endogenize the participation decision. $^{27}$

In sum, a consensus seems to be emerging that incomplete markets and heterogeneity have significant implications for asset pricing, but that these features alone cannot fully resolve the equity premium puzzle (see, e.g., Kocherlakota 1996; Heaton and Lucas 2007).

\section{Concluding remarks}

Heterogeneous agent models have become the norm, rather than the exception, in macroeconomics. They provide a useful synthesis between the macro approach to economic questions, grounded in dynamic recursive equilibrium theory, and the micro approach focused on heterogeneity among individuals in their innate characteristics, their luck, and their choices.

Among heterogeneous-agent economies, the standard incomplete markets (SIM) model is already a workhorse of quantitative macroeconomics. The first generation of SIM models took a fairly narrow view of risk (only exogenous endowment shocks), of insurance (only saving), and of the interaction between aggregate and idiosyncratic shocks (none). However, the greatest

\footnotetext{
${ }^{27}$ Along these lines, Gomes and Michaelides (2008) propose a life-cycle model where agents differ in risk aversion and EIS. Agents with a high EIS accumulate most of the wealth, and end up holding most of the stocks. Consequently, aggregate risk is concentrated on them.
} 
strength of this framework has proven to be its flexibility. Macroeconomic research in the past decade has demonstrated that the SIM model can be successfully extended in all three directions.

Given the burgeoning literature, it would be difficult to do justice to all contributions in this area, and we have undoubtedly neglected lots of interesting work in this survey. Nevertheless, we have tried to describe some of the important progress that has been made, and to highlight some challenges on the horizon. We conclude by summarizing what we think are some of the priorities for heterogeneous agent macroeconomics.

With respect to the sources of heterogeneity, macroeconomic models should be systematically extended to incorporate additional sources of risk in addition to individual labor productivity shocks. In the same vein as the real business cycle literature, which, with time, recognized the importance of additional sources of aggregate fluctuations beyond shocks to total factor productivity, heterogeneous agent macroeconomics should come to terms with the fact that some of the biggest risks in the lottery of life are connected to parental background, health status, and family dynamics. Including additional relevant sources of heterogeneity will make it possible to refine our answers to existing quantitative questions, and will allow us to evaluate a broader set of policy issues.

As to the channels of insurance, the SIM model should be developed to overcome two important criticisms. First, from a theoretical perspective, the market structure is assumed exogenously, hence the model is subject to a version of the Lucas critique: public policies have a limited impact on private risk sharing. The most recent generation of SIM models takes this critique more seriously and includes setups with endogenous borrowing limits, in the spirit of the endogenous incomplete markets literature. Second, from an empirical perspective, the baseline SIM model seems to offer too few insurance possibilities relative to the data. More work should be devoted to quantify the overall degree of insurance faced by households in actual economies, and to include in models the most prominent channels of insurance in order to close the gap with the data. Both these issues are key for policy questions, where the extent of private insurance and the degree of crowding out between private and public insurance must both be of the right size to deliver reliable answers.

Finally, future research should address more thoroughly the relationship between aggregate and individual uncertainty. The view that the two sources of risk have, at most, a statistical 
correlation, but no deep common driving source is overly simplistic. We need economic microfoundations relating aggregate and idiosyncratic risk. There are good reasons to suppose that a range of macroeconomic developments have implications for both aggregates and for dispersion. Technological change and increased competition - perhaps resulting from increased openness to trade - might increase both average productivity and simultaneously increase volatility and dispersion in individual earnings. Alternatively, in a world of asymmetric information, changes in the relative quality of public versus private signals could move both means and variances: Veldkamp (2007) surveys this nascent literature. Search and matching models offer another framework with a natural interaction between aggregate and idiosyncratic risk: shocks to aggregate productivity can, in principle, lead to waves of match creation and destruction. More work needs to be done on integrating labor market frictions of this type into models with risk-averse agents and incomplete markets.

These issues are important because a deeper theory of how aggregate and idiosyncratic fluctuations are connected will allow us to go much further in understanding the extent to which heterogeneity coupled with market incompleteness amplifies the effect of aggregate shocks, and the extent to which aggregate shocks affect inequality.

The main motivation for developing a deeper theory of the interaction between aggregate and idiosyncratic risk, however, is the same as for enriching our models of risk and of insurance: it makes the framework much more useful for policy analysis. In particular, work in this direction will take us closer to delivering on the promise held out by Lucas (2003). He points out that this class of models can potentially be used to study, in a unified way, aggregate stabilization policies that reduce output fluctuations, and social insurance policies that reallocate resources among households. The key novelty is in the ability to evaluate the distributional impact of aggregate stabilization policies, and the business cycle implications of social insurance policies. 


\section{References}

[1] Abowd JM, Card D. 1989. On the covariance structure of earnings and hours changes. Econometrica 57(2):411-45.

[2] Abraham A, Pavoni N. Forthcoming. Efficient allocations with moral hazard and hidden borrowing and lending: A recursive formulation. Review of Economic Dynamics.

[3] Aiyagari SR. 1994. Uninsured idiosyncratic risk and aggregate saving. Quarterly Journal of Economics 109(3):659-84.

[4] Aiyagari SR, Gertler M. 1991. Asset returns with transaction costs and uninsured individual risks. Journal of Monetary Economics 27(3):311-31.

[5] Aiyagari SR, Greenwood J, Guner N. 2000. On the state of the union. Journal of Political Economy 108(2):213-44.

[6] Aiyagari SR, McGrattan ER. 1998. The optimum quantity of debt. Journal of Monetary Economics 42(3):447-69.

[7] Albanesi S. 2007. Inflation and inequality. Journal of Monetary Economics. 54(4):1088114.

[8] Allen F. 1985. Repeated principal-agent relationships with lending and borrowing. Economics Letters 17(1-2):27-31.

[9] Angeletos G, Calvet L. 2006. Idiosyncratic production risk, growth and the business cycle. Journal of Monetary Economics 53(6):1095-115.

[10] Athreya KB. 2002. Welfare implications of the Bankruptcy Reform Act of 1999. Journal of Monetary Economics 49(8):1567-95.

[11] Attanasio OP, Banks J, Tanner S. 2002. Asset holding and consumption volatility. Journal of Political Economy 110(4):771-92.

[12] Attanasio OP, Davis SJ. 1996. Relative wage movements and the distribution of consumption. Journal of Political Economy 104(6):1227-62. 
[13] Attanasio OP, Kitao S, Violante GL. 2008. Financing Medicare: A general equilibrium analysis, in Demography and Economics, edited by Shoven J.

[14] Attanasio OP, Low H, Sánchez-Marcos V. 2005. Female labor supply as insurance against idiosyncratic risk. Journal of the European Economic Association 3(2-3):755-64.

[15] Attanasio OP, Pavoni N. 2008. Risk sharing in private information models with asset accumulation: Explaining the excess smoothness of consumption. Mimeo, University College London.

[16] Attanasio OP, Ríos-Rull J-V. 2000. Consumption smoothing in island economies: Can public insurance reduce welfare? European Economic Review 44(7):1225-58.

[17] Auerbach AJ, Kotlikoff LJ. 1987. Dynamic Fiscal Policy. Cambridge: Cambridge University Press.

[18] Baker M. 1997. Growth-rate heterogeneity and the covariance structure of life-cycle earnings. Journal of Labor Economics 15(2):338-75.

[19] Bansal R, Yaron A. 1994. Risks for the long run: A potential resolution of asset pricing puzzles. Journal of Finance 59:1481-509.

[20] Bewley T. 1977. The permanent income hypothesis: A theoretical formulation. Journal of Economic Theory 16(2):252-92.

[21] Bewley T. 1983. A difficulty with the optimum quantity of money. Econometrica $51(5): 1485-504$.

[22] Blundell R, Pistaferri L, Preston I. Forthcoming. Consumption inequality and partial insurance. American Economic Review.

[23] Blundell R, Preston I. 1998. Consumption inequality and income uncertainty. Quarterly Journal of Economics 113(2):603-40.

[24] Bourguignon FJ, Browning M, Chiappori P, Lechene V. 1993. Intra household allocation of consumption: A model and some evidence from French data. Annales d'Economie et Statistiques 29:137-56. 
[25] Brav A, Constantinides GM, Geczy CC. 2002. Asset pricing with heterogeneous consumers and limited participation: Empirical evidence. Journal of Political Economy 110(4):793-824.

[26] Browning M, Hansen LP, Heckman JJ. 1999. Micro data and general equilibrium models, in Handbook of Macroeconomics, edited by Taylor J, Woodford M. Amsterdam: Elsevier.

[27] Budria S, Díaz-Giménez J., Quadrini V, Rios-Rull J-V. 2002. Updated facts on the U.S. distributions of earnings, income, and wealth. Federal Reserve Bank of Minneapolis Quarterly Review 26(3):2-35.

[28] Cagetti M, De Nardi M. 2006. Entrepreneurship, frictions, and wealth. Journal of Political Economy 114(5):835-70.

[29] Cagetti M, De Nardi M. 2008. Wealth inequality: Data and models. Macroeconomic Dynamics 12(52):285-313.

[30] Carroll CD. 1997. Buffer-stock saving and the life cycle/permanent income hypothesis. Quarterly Journal of Economics 112(1):1-55.

[31] Case A, Lubotsky D, Paxson C. 2002. Economic status and health in childhood: The origins of the gradient. American Economic Review 92(5):1308-34.

[32] Caselli F, Ventura J. 2000. A representative consumer theory of distribution. American Economic Review 90(4):909-26.

[33] Castañeda A, Díaz-Giménez J, Ríos-Rull J-V. 2003. Accounting for the US earnings and wealth inequality. Journal of Political Economy 111(4):818-57.

[34] Chamberlain G, Wilson CA 2000. Optimal intertemporal consumption under uncertainty. Review of Economic Dynamics 3(3):365-95.

[35] Chambers MS, Garriga C, Schlagenhauf DE. 2008. The loan structure and housing tenure decisions in an equilibrium model of mortgage choice. Mimeo, Towson University.

[36] Chatterjee S. 1994. Transitional dynamics and the distribution of wealth in a neoclassical growth model. Journal of Public Economics 54(1):97-119. 
[37] Chatterjee S, Corbae D, Nakajima M, Ríos-Rull J-V. 2007. A quantitative theory of unsecured consumer credit with risk of default. Econometrica 75(6):1525-89.

[38] Chien Y, Cole HL, Lustig H. 2008. A multiplier approach to understanding the macro implications of household finance. Mimeo, University of Pennsylvania.

[39] Christiano LJ, Eichenbaum M. 1992. Current Real-Business Cycle Theories and Aggregate Labor-Market Fluctuations. American Economic Review 82(3):430-450.

[40] Cole HL, Kocherlakota NR. 2001. Efficient allocations with hidden income and hidden storage. Review of Economic Studies 68(3):523-42.

[41] Conesa JC, Kitao S, Krueger D. Forthcoming. Taxing Capital? Not a Bad Idea After All! American Economic Review.

[42] Conesa JC, Krueger D. 1999. Social security reform with heterogeneous agents. Review of Economic Dynamics 2(4):757-95.

[43] Conesa JC, Krueger D. 2006. On the optimal progressivity of the income tax code. Journal of Monetary Economics 53(7):1425-50.

[44] Constantinides GM, Duffie D. 1996. Asset pricing with heterogeneous consumers. Journal of Political Economy 104(2):219-40.

[45] Cubeddu L, Ríos-Rull J-V. 2003. Families as shocks. Journal of the European Economic Association 1(2-3):671-82.

[46] Cunha F, Heckman J, Navarro S. 2005. Separating uncertainty from heterogeneity in life cycle earnings. Oxford Economic Papers 57(2):191-261.

[47] Davila J, Hong JH, Krusell P, Ríos-Rull J-V. 2005. Constrained efficiency in the neoclassical growth model with uninsurable idiosyncratic shocks. PIER Working Paper 05-023, University of Pennsylvania.

[48] Davis MA, Heathcote, J. 2007. The price and quantity of residential land in the United States. Journal of Monetary Economics 54(8):2595-620.

[49] Deaton A. 1991. Saving and liquidity constraints. Econometrica 59(5):1221-48. 
[50] Deaton A, Paxson C. 1994. Intertemporal choice and inequality. Journal of Political Economy 102(3):437-67.

[51] De Nardi M, French M, Jones JB. 2006. Differential mortality, uncertain medical expenses, and the saving of elderly singles. Working Paper 12554, National Bureau of Economic Research.

[52] De Santis M. 2007. Individual consumption risk and the welfare cost of business cycles. American Economic Review 97(4):1488-1506.

[53] Díaz-Giménez J, Prescott EC, Fitzgerald T, Alvarez F. 1992. Banking in computable general equilibrium economies. Journal of Economic Dynamics and Control 16(3-4):53359.

[54] Doepke M, Schneider M. 2006. Inflation and the redistribution of nominal wealth. Journal of Political Economy 114(6):1069-97.

[55] Domeij D, Flodén M. 2006. The labor-supply elasticity and borrowing constraints: Why estimates are biased. Review of Economic Dynamics 9(2):242-62.

[56] Domeij D, Heathcote J. 2004. On the distributional effects of reducing capital taxes. International Economic Review 45(2):523-54.

[57] Erosa A, Ventura G. 2002. On inflation as a regressive consumption tax. Journal of Monetary Economics 49(4):761-95.

[58] Fernandez R, Rogerson R. 2003. Equity and resources: An analysis of education finance systems. Journal of Political Economy 111(4):858-97.

[59] Fernández-Villaverde J, Krueger D. 2002. Consumption and saving over the life cycle: How important are consumer durables? Proceedings of the 2002 North American Summer Meetings of the Econometric Society.

[60] Fisher J, Johnson D. 2006. Consumption mobility in the United States: Evidence from two panel data sets. B.E. Journal of Economic Analysis \& Policy 6(1):art. 16. available at http://www.bepress.com/bejcap/topics/vol6/iss1/art16. 
[61] Flodén M. 2001. The effectiveness of government debt and transfers as insurance. Journal of Monetary Economics 48(1):81-108.

[62] Flodén M. 2006. Labour supply and saving under uncertainty. Economic Journal 116(513):721-37.

[63] Flodén M. 2008. Aggregate Savings When Individual Income Varies. Review of Economic Dynamics 11(1):70-82.

[64] Fogli A. 2004. Endogenous labor market rigidities and family ties. Mimeo, University of Minnesota.

[65] French E, Jones JB. 2004. On the distribution and dynamics of health care costs. Journal of Applied Econometrics 19(6):705-21.

[66] Gomes F, Michaelides A. 2008. Asset Pricing with Limited Risk Sharing and Heterogeneous Agents. Review of Financial Studies 21(1):415-448.

[67] Gottschalk P, Moffitt RA. 1994. The growth of earnings instability in the U.S. labor market. Brookings Papers on Economic Activity 25(1994-2):217-72.

[68] Gourinchas P-O, Parker JA. 2002. Consumption over the life cycle. Econometrica $70(1): 47-89$.

[69] Greenwood J, Guner N, Knowles JA. 2003. More on marriage, fertility, and the distribution of income. International Economic Review 44(3):827-62.

[70] Guiso L, Pistaferri L, Schivardi F. 2005. Insurance within the firm. Journal of Political Economy 113(5):1054-87.

[71] Guvenen F. 2006. A parsimonious macroeconomic model for asset pricing. Mimeo, University of Minnesota.

[72] Guvenen F. 2007. Learning your earning: Are labor income shocks really very persistent? American Economic Review 97(3):687-712.

[73] Guvenen F. Forthcoming. An empirical investigation of labor income processes. Review of Economic Dynamics. 
[74] Guvenen F, Smith AA. 2008. Inferring labor income risk from economic choices: An indirect inference approach. Mimeo, University of Minnesota.

[75] Haider SJ. 2001. Earnings instability and earnings inequality of males in the United States: 1967-1991. Journal of Labor Economics 19(4):799-836.

[76] Hansen GD. 1985. Indivisible labor and the business cycle. Journal of Monetary Economics 16(3):309-27.

[77] Hansen GD, Imrohoroglu A. 1992. The role of unemployment insurance in an economy with liquidity constraints and moral hazard. Journal of Political Economy 100(1):118-42.

[78] Hassler J, Rodríguez-Mora JV, Storesletten K, Zilibotti F. 2005. A positive theory of geographical mobility and social insurance. International Economic Review 46(1):263303.

[79] Heathcote J. 2005. Fiscal policy with heterogeneous agents and incomplete markets. Review of Economic Studies 72(1):161-88.

[80] Heathcote J, Storesletten K, Violante GL. 2005. Two views of inequality over the life cycle. Journal of the European Economic Association 3(2-3):765-75.

[81] Heathcote J, Storesletten K, Violante GL. 2007. Consumption and labor supply with partial insurance: An analytical framework. Mimeo, New York University.

[82] Heathcote J, Storesletten K, Violante GL. 2008a. Insurance and opportunities: a welfare analysis of labor market risk. Journal of Monetary Economics 55(3):501-25.

[83] Heathcote J, Storesletten K, Violante GL. 2008b. The macroeconomic implications of rising wage inequality in the United States. Mimeo, New York University.

[84] Heaton J, Lucas DJ. 1996. Evaluating the effects of incomplete markets on risk sharing and asset pricing. Journal of Political Economy 104(3):443-87.

[85] Heaton J, Lucas D. 2000. Portfolio choice in the presence of background risk. Economic Journal 110(460):1-26. 
[86] Heaton J, Lucas D. 2007. Can heterogeneity, undiversifiable risk, and trading frictions explain the equity premium? in Handbook of the Equity Risk Premium, edited by Mehra R. Amsterdam: Elsevier.

[87] Heckman JJ. 2001. Micro data, heterogeneity, and the evaluation of public policy: Nobel lecture. Journal of Political Economy 109(4):673-748.

[88] Heckman JJ, Lochner L, Taber C. 1998. Explaining rising wage inequality: Explanations with a dynamic general equilibrium model of labor earnings with heterogeneous agents. Review of Economic Dynamics 1(1):1-58.

[89] Hong JH, Ríos-Rull J-V. 2007. Social security, life insurance and annuities for families. Journal of Monetary Economics 54(1):118-40.

[90] Hosseini R. 2008. Adverse selection in the annuity market and the role for social security. Mimeo, University of Rochester.

[91] Hubbard RG, Judd KL. 1986. Liquidity Constraints, Fiscal Policy, and Consumption. Brookings Papers on Economic Activity 17(1):1-60.

[92] Hubbard RG, Skinner J, Zeldes SP. 1995. Precautionary saving and social insurance. Journal of Political Economy 103(2):360-99.

[93] Huggett M. 1993. The risk-free rate in heterogeneous-agent incomplete-insurance economies. Journal of Economic Dynamics and Control 17(5-6):953-69.

[94] Huggett M. 1996. Wealth distribution in life-cycle economies. Journal of Monetary Economics 38(3):469-94.

[95] Huggett M, 1997. The one-sector growth model with idiosyncratic shocks: Steady states and dynamics. Journal of Monetary Economics 39(3):385-403.

[96] Huggett M, Ospina S. 2001. Aggregate precautionary savings: When is the third derivative irrelevant? Journal of Monetary Economics 48(2):373-96.

[97] Huggett M, Parra JC. 2008. Quantifying the inefficiency of the US social insurance system. Mimeo, Georgetown University. 
[98] Huggett M, Ventura G. 1999. On the distributional effects of social security reform. Review of Economic Dynamics 2(3):498-531.

[99] Huggett M, Ventura G, Yaron A. 2006. Sources of Lifetime Inequality. Working Paper 13224, National Bureau of Economic Research.

[100] Imrohoroglu, A. 1989. Cost of business cycles with indivisibilities and liquidity constraints. Journal of Political Economy 97(6):1364-83.

[101] Imrohoroglu, A. 1992. The welfare cost of inflation under imperfect insurance. Journal of Economic Dynamics and Control 16(1):79-91.

[102] Imrohoroglu A, Imrohoroglu S, Joines DH. 1995. A life cycle analysis of social security. Economic Theory 6(1):83-114.

[103] Jappelli T, Pistaferri L. 2000. Using subjective income expectations to test for excess sensitivity of consumption to predicted income growth. European Economic Review $44(2): 337-58$.

[104] Jappelli T, Pistaferri L. 2006. Intertemporal choice and consumption mobility. Journal of the European Economic Association 4(1):75-115.

[105] Jeske K, Kitao S. 2007. US tax policy and health insurance demand: Can a regressive policy improve welfare? Working Paper 2007-13, Federal Reserve Bank of Atlanta.

[106] Kambourov G, Manovski I. Forthcoming. Occupational mobility and wage inequality. Review of Economic Studies.

[107] Kaplan, G. 2007. Moving back home: Insurance against labor market risk. Mimeo, New York University.

[108] Kaplan, G. Violante GL. 2008. How much insurance in Bewley models? Mimeo, New York University.

[109] Keane MP, Wolpin KI. 1997. The career decisions of young men. Journal of Political Economy 105(3):473-522. 
[110] Kimball MS. 1990. Precautionary saving in the small and in the large. Econometrica 58(1):53-73.

[111] Kiyotaki N, Michaelides A, Nikolov K. 2007. Winners and losers in housing markets. Mimeo, Princeton University.

[112] Kocherlakota NR. 1996. Implications of efficient risk sharing without commitment. Review of Economic Studies 63(4):595-609.

[113] Krebs T. 2003. Growth and Welfare Effects of Business Cycles in Economies with Idiosyncratic Human Capital Risk. Review of Economic Dynamics 6(4):846-868.

[114] Krebs T. 2007. Job displacement risk and the cost of business cycles. American Economic Review 97(3):664-86.

[115] Krueger D, Kubler F. 2004. Computing equilibrium in OLG models with stochastic production. Journal of Economic Dynamics and Control 28(7):1411-1436.

[116] Krueger D, Ludwig A. 2007. On the consequences of demographic change for rates of returns to capital, and the distribution of wealth and welfare. Journal of Monetary Economics 54(1):49-87.

[117] Krueger D, Lustig H. 2006. When is market incompleteness irrelevant for the price of aggregate risk (and when is it not)? Working Paper 12634, National Bureau of Economic Research.

[118] Krueger D, Perri F. 2003. On the welfare consequences of the increase in inequality in the United States, in NBER Macroeconomics Annual 2003, edited by Gertler M, Rogoff K, 83-121. Cambridge, MA: MIT Press.

[119] Krueger D, Perri F. 2005. Public versus private risk sharing. Mimeo, University of Pennsylvania.

[120] Krueger D, Perri F. 2006. Does income inequality lead to consumption inequality? Evidence and theory. Review of Economic Studies 73(1):163-93. 
[121] Krusell P, Mukoyama T, Sahin A. 2007. Labor-market matching with precautionary savings and aggregate fluctuations. Manuscript, Princeton University.

[122] Krusell P, Mukoyama T, Sahin A, Smith AA. Forthcoming. Revisiting the welfare effects of eliminating business cycles. Review of Economic Dynamics.

[123] Krusell P, Smith AA. 1997. Income and wealth heterogeneity, portfolio choice, and equilibrium asset returns. Macroeconomic Dynamics 1(2):387-422.

[124] Krusell P, Smith AA. 1998. Income and wealth heterogeneity in the macroeconomy. Journal of Political Economy 106(5):867-96.

[125] Krusell P, Smith AA. 1999. On the Welfare Effects of Eliminating Business Cycles. Review of Economic Dynamics 2(1):245-272.

[126] Krusell P, Smith AA. 2006. Quantitative macroeconomic models with heterogeneous agents, in Advances in Economics and Econometrics: Theory and Applications, edited by Blundell R, Newey W, T Persson. Cambridge: Cambridge University Press.

[127] Kydland FE. 1984. Labor-force heterogeneity and the business cycle. Carnegie-Rochester Conference Series on Public Policy 21:173-208.

[128] Kydland FE, Prescott EC. 1982. Time to build and aggregate fluctuations. Econometrica 50(6):1345-70.

[129] Laitner J. 1979. Household bequests, perfect expectations, and the national distribution of wealth. Econometrica 47(5):1175-93.

[130] Lentz R. Forthcoming. Optimal unemployment insurance in an estimated job search model with savings. Review of Economic Dynamics.

[131] Levine DK, Zame WR. 2002. Does market incompleteness matter? Econometrica 70(5):1805-39.

[132] Ligon E. 2002. Dynamic bargaining in households (with an application to Bangladesh). Mimeo, University of California, Berkeley. 
[133] Lillard LA, Weiss Y. 1979. Components of variation in panel earnings data: American scientists, 1960-70. Econometrica 47(2):437-54.

[134] Lillard LA, Willis RJ. 1978. Dynamic aspects of earning mobility. Econometrica 46(5):985-1012.

[135] Lise J. 2007. On-the-job search and precautionary savings: Theory and empirics of earnings and wealth inequality. Mimeo, University College London.

[136] Lise J, Seitz S. Forthcoming. Consumption inequality and intra-household allocations. Review of Economic Studies.

[137] Livshits I, MacGee J, Tertilt M. 2007. Consumer bankruptcy: A fresh start. American Economic Review 97(1):402-18.

[138] Ljungqvist L, Sargent TJ. 2004. Recursive Macroeconomic Theory. Cambridge, MA: MIT Press.

[139] Low H. 2005. Self-insurance in a life-cycle model of labor supply and savings. Review of Economic Dynamics 8(4):945-75.

[140] Low H, Meghir C, Pistaferri, L. 2007. Wage risk and employment risk over the life cycle. Discussion Paper 6187, Centre for Economic Policy Research.

[141] Lucas DJ. 1994. Asset pricing with undiversifiable income risk and short sales constraints: Deepening the equity premium puzzle. Journal of Monetary Economics 34(3):325-41.

[142] Lucas RE. 1978. Asset prices in an exchange economy. Econometrica 46(6):1429-45.

[143] Lucas RE. 1987. Models of Business Cycles. New York: Basil Blackwell.

[144] Lucas RE. 1992. On efficiency and distribution. Economic Journal 102(411):233-47.

[145] Lucas RE. 2003. Macroeconomic priorities. American Economic Review 93(1):1-14.

[146] MaCurdy TE. 1982. The use of time series processes to model the error structure of earnings in a longitudinal data analysis. Journal of Econometrics 18(1):83-114. 
[147] Maliar L, Maliar S. 2003. The representative consumer in the neoclassical growth model with idiosyncratic shocks. Review of Economic Dynamics 6(2):362-80.

[148] Mankiw NG. 1986. The equity premium and the concentration of aggregate shocks. Journal of Financial Economics 17(1):211-19.

[149] Marcet A, Obiols-Homs F, Weil P. 2007. Incomplete markets, labor supply and capital accumulation. Journal of Monetary Economics 54(8):2621-35.

[150] Massa M, Simonov A. 2006. Hedging, familiarity and portfolio choice. Review of Financial Studies 19(2):633-85.

[151] Mazzocco M. 2007. Household intertemporal behaviour: A collective characterization and a test of commitment. Review of Economic Studies 74(3):857-95.

[152] McClellan M, Skinner J. 2006. The incidence of Medicare. Journal of Public Economics 90(1-2):257-76.

[153] Meghir C, Pistaferri M. 2004. Income variance dynamics and heterogeneity. Econometrica $72(1): 1-32$.

[154] Mehra R, Prescott EC. 1985. The equity premium: A puzzle. Journal of Monetary Economics 15(2):145-61.

[155] Miao J. 2006. Competitive equilibria of economies with a continuum of consumers and aggregate shocks. Journal of Economic Theory 128(1):274-98.

[156] Mulligan CB. 1997. Parental Priorities and Economic Inequality. Chicago: University of Chicago Press.

[157] Nishiyama S. 2002. Bequests, inter vivos transfers, and wealth distribution. Review of Economic Dynamics 5(4):892-931.

[158] Nishiyama S, Smetters KA. 2005. Consumption taxes and economic efficiency with idiosyncratic wage shocks. Journal of Political Economy 113(5):1088-1115.

[159] Palumbo MG. 1999. Uncertain medical expenses and precautionary saving near the end of the life cycle. Review of Economic Studies 66(2):395-421. 
[160] Pijoan-Mas J. 2006. Precautionary savings or working longer hours? Review of Economic Dynamics 9(2):326-52.

[161] Pistaferri L. 2003. Anticipated and unanticipated wage changes, wage risk, and intertemporal labor supply. Journal of Labor Economics 21(3):729-82.

[162] Postel-Vinay F, Turon H. 2008. On-the-job search, productivity shocks, and the individual earnings process. Mimeo, University of Bristol.

[163] Primiceri G, van Rens T. Forthcoming. Heterogeneous life-cycle profiles. Journal of Monetary Economics.

[164] Quadrini V. 2000. Entrepreneurship, saving and social mobility. Review of Economic Dynamics 3(1):1-40.

[165] Regalia F, Ríos-Rull J-V. 2001. What accounts for the increase in the number of single households? Mimeo, University of Pennsylvania.

[166] Ríos-Rull J-V. 1993. Working in the market, working at home, and the acquisition of skills: A general-equilibrium approach. American Economic Review 83(4):893-907.

[167] Ríos-Rull J-V. 1994. On the quantitative importance of market completeness. Journal of Monetary Economics 34(3):463-96.

[168] Ríos-Rull J-V. 1995. Models with heterogeneous agents. In Frontiers of Business Cycle Research, edited by Cooley TF. Princeton, NJ: Princeton University Press.

[169] Rogerson R. 1988. Indivisible labor, lotteries and equilibrium. Journal of Monetary Economics 21(1):3-16.

[170] Schechtman J. 1976. An income fluctuation problem. Journal of Economic Theory $12(2): 218-41$.

[171] Schechtman J, Escudero VLS. 1977. Some results on "an income fluctuation problem." Journal of Economic Theory 16(2):151-66.

[172] Schulhofer-Wohl S. Forthcoming. Heterogeneous risk preferences and the welfare cost of business cycles. Review of Economic Dynamics. 
[173] Sinclair SH, Smetters KA. 2004. Health shocks and the demand for annuities. Technical Paper Series (9), Congressional Budget Office, Washington DC.

[174] Storesletten K, Telmer CI, Yaron A. 1999. The risk-sharing implications of alternative social security arrangements. Carnegie-Rochester Conference Series on Public Policy 50:213-59.

[175] Storesletten K, Telmer CI, Yaron A. 2001. The welfare cost of business cycles revisited: Finite lives and cyclical variation in idiosyncratic risk. European Economic Review 45(7):1311-39.

[176] Storesletten K, Telmer CI, Yaron A. 2004a. Consumption and risk sharing over the life cycle. Journal of Monetary Economics 51(3):609-33.

[177] Storesletten K, Telmer CI, Yaron A. 2004b. Cyclical dynamics in idiosyncratic labor market risk. Journal of Political Economy 112(3):695-717.

[178] Storesletten K, Telmer CI, Yaron A. 2007. Asset pricing with idiosyncratic risk and overlapping generations. Review of Economic Dynamics 10(4):519-48.

[179] Telmer CI. 1993. Asset-pricing puzzles and incomplete markets. Journal of Finance 48(5):1803-32.

[180] Veldkamp LL. 2007. Information choice in macroeconomics and finance. Manuscript, New York University.

[181] Venti SF, Wise DA. 2001. Aging and housing equity: Another look. Working Paper 8608, National Bureau of Economic Research.

[182] Vissing-Jørgensen A. 2002. Limited asset market participation and the elasticity of intertemporal substitution. Journal of Political Economy 110(4):825-53.

[183] Zhang HH. 1997. Endogenous borrowing constraints with incomplete markets. Journal of Finance 52(5):2187-209. 